NiLS BÜTTNER

\title{
"... is said to follow the light of the Sun «- Van Dycks Selbstbildnis mit der Sonnenblume ${ }^{1}$
}

Im März des Jahres 1632 traf Anthonis Van Dyck (1599-164I) aus Antwerpen in London ein - zu seinem Reisegepäck gehörten zahlreiche Gemälde. Dank seiner guten Kontakte zu Thomas Howard, Graf von Arundel und Surrey (1585-1646), den er schon zu Beginn der zwanziger Jahre kennengelernt hatte, zu Kenelm Digby (1603-1665), Endymion Porter (15871649) und anderen Angehörigen der englischen Aristokratie, hatte Van Dyck schnell Zugang zum Hof gefunden. Arundel stand im Zentrum des kulturellen Lebens seiner Zeit. ${ }^{2}$ Wohl nicht zuletzt dank seiner Fürsprache hatte Van Dyck schon bald nach der Ankunft in England einige Gemälde an König Karl I. (I600-1649) verkauft und den Auftrag erhalten, mehrere Mitglieder der königlichen Familie zu porträtieren. ${ }^{3}$ Nachdem er anfangs bei dem Miniaturisten Edward Norgate (vor 1581-1650) Quartier genommen hatte, der zum engeren Umkreis Arundels gehörte, gab der König bald schon Befehl, für eine würdigere Unterbringung $\mathrm{zu}$ sorgen. $\mathrm{Er}$ wies einen seiner Beamten an, diesbezüglich mit dem Architekten Inigo Jones (1571-I653) zu sprechen. In Blackfriars an der Themse wurde ein passendes Haus gefunden, das für den ausländischen Maler zugleich den Vorteil hatte, außerhalb des Einflußbereichs der Londoner Malergilde, der »Painter-Stainers Company«, zu liegen. Als Sommersitz wurde dem Künstler eine Wohnung

I Mein Dank gilt Dr. Ursula Härting, Hamm, die mich auf das Thema aufmerksam machte und Prof. Dr. Barbara Welzel, Dortmund, die mich ermutigte, aus einer Idee einen Aufsatz werden zu lassen, den sie durch kritische Lektüre förderte. Dr. Ulrich Heinen, Köln, hat das Entstehen dieses Beitrages aufmerksam verfolgt und durch seine Hinweise und Ratschläge tatkräftig unterstützt. Für anregende Diskussionen danke ich neben meiner Frau, Ulrike Büttner, meinen Braunschweiger Kolleginnen Dr. Irmgard Müsch und Dr. Mila Horký. im wenige Meilen von London entfernt gelegenen Schloß Eltham angewiesen. ${ }^{4}$ Ihren höchsten Ausdruck fand die königliche Gunst am 5.Juli des Jahres I632, als Van Dyck mit der Ernennung zum "principalle Paynter in ordinary to their Majesties« zum Ritter geschlagen und in den Adelsstand erhoben wurde. Noch im selben Jahr billigte Karl I. dem Maler ein jährliches Salär von 200 Pfund zu, unangesehen dessen Van Dyck für sämtliche Porträtaufträge noch gesondert bezahlt wurde - und derer gab es viele.'

Das vielleicht ungewöhnlichste Werk, das in jenen Jahren entstand, ist ein Selbstbildnis, das den Künstler vor einer in voller Blüte stehenden Sonnenblume zeigt (Abb. I). ${ }^{6}$ Weder die Provenienz des Bildes, noch die näheren Umstände seiner Entstehung sind bekannt. Ungewöhnlich für ein Porträt ist das auf Leinwand ausgeführte Gemälde in einem breit gelagerten Querformat angelegt. ${ }^{7}$ Es zeigt den Maler, der mit der rechten Hand auf die prächtige Sonnenblume deutet, schräg von hinten. Die Blume, deren kräftiges Gelb durch das Blau des im Hintergrund gezeigten Himmels noch betont wird, nimmt beinahe die gesamte rechte Hälfte des Bildes ein. Der Ausschnitt ist so knapp gewählt, daß der weisende rechte Arm des Künstlers vom unteren Bildrand überschnitten wird. Zugleich präsentiert Van Dyck, den Blick über die Schulter gewandt, mit der Linken eine goldene Kette. Immer wie-

$2 \mathrm{Zu}$ Van Dycks Kontakten vgl. Insa Christiane Hennen, "Karl zu Pferder: Ikonologische Studien zu Anton van Dycks Reiterporträts Karls I. von England, Frankfurt a.M./Berlin u.a. 1995 (= Europäische Hochschulschriften, Bd. 28), I I- I 5. - Allgemein zu Van Dyck in England auch: Malcolm Rogers, in: Christopher Brown u. Hans Vlieghe (Hrg.), Van Dyck IS99-164I, Ausst.kat. Koninklijk Museum voor Schone Kunsten, Antwerpen, Royal Academy of Arts, London/Antwerpen 1999, 79-91, mit weiterer Literatur. - David Jaffé, Earl and Countes of Arundel: Renaissance Collectors, in: Apollo, CXLIV, 1996, 9-ı1. - Allgemein zum Arun- 


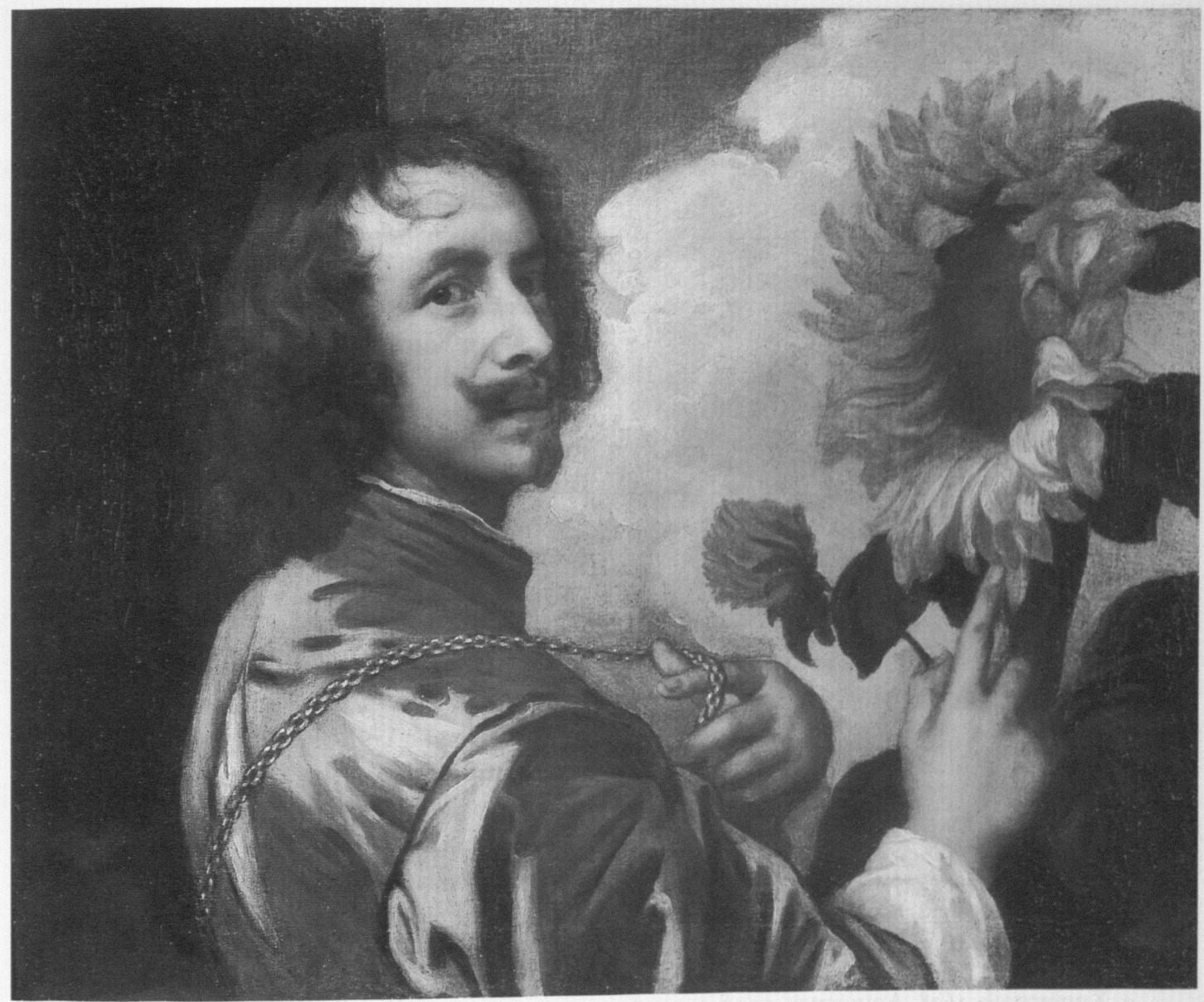

I. Anthonis Van Dyck, Selbstbildnis mit der Sonnenblume, Öl auf Leinwand, $60 \times 73 \mathrm{~cm}$. London, By Permission of the Duke of Westminster

der wurde vermutet, daß sie in einem direkten Zusammenhang mit seiner Biographie steht: Van Dyck hatte nämlich von Karl I. eine solche

del-Kreis: David Howarth, Lord Arundel and his Circle, New Haven/ London 1985.

3 Eric Larsen, The Paintings of Anthony van Dyck, Bd. II, Freren I 988, 293 f. - Oliver Millar (Bearb.), Van Dyck in England, Ausst.-kat. National Portrait Gallery, London $1982,18$.

4 Millar (wie Anm.3), r8f. - F. Jos. Van den Branden, Geschiedenis der Antwerpsche Schilderschool, Antwerpen $188_{3}, 724 \mathrm{f}$.

5 Millar (wie Anm. 3), 20.

6 Selbstbildnis mit der Sonnenblume, Öl auf Leinwand, $60 \times 73 \mathrm{~cm}$. London, By Permission of the Duke of
Ehrenkette im Wert von iro Pfund zum Geschenk erhalten. Die Kette, die mit einem von Diamanten eingefaßten Miniaturbildnis des

Westminster. Vgl. Larsen (wie Anm.3), Bd. II, 398, Nr. 1019. - Ausst.-kat. Antwerpen/London (wie Anm. 2), 244, Nr. 66, mit Bibliographie.

7 J. Douglas Stewart hat zurecht auf das ungewöhn-liche Format hingewiesen. Er vermutete deshalb, daß das Bild für einen bestimmten Platz entstanden sei, "probably an overdoor «. Vgl. Arthur K. Wheelock Jr. (Hrg.), Anthony van Dyck, Ausst.-kat. National Gallery of Art, Washington (DC) 1990-1991, 71. 


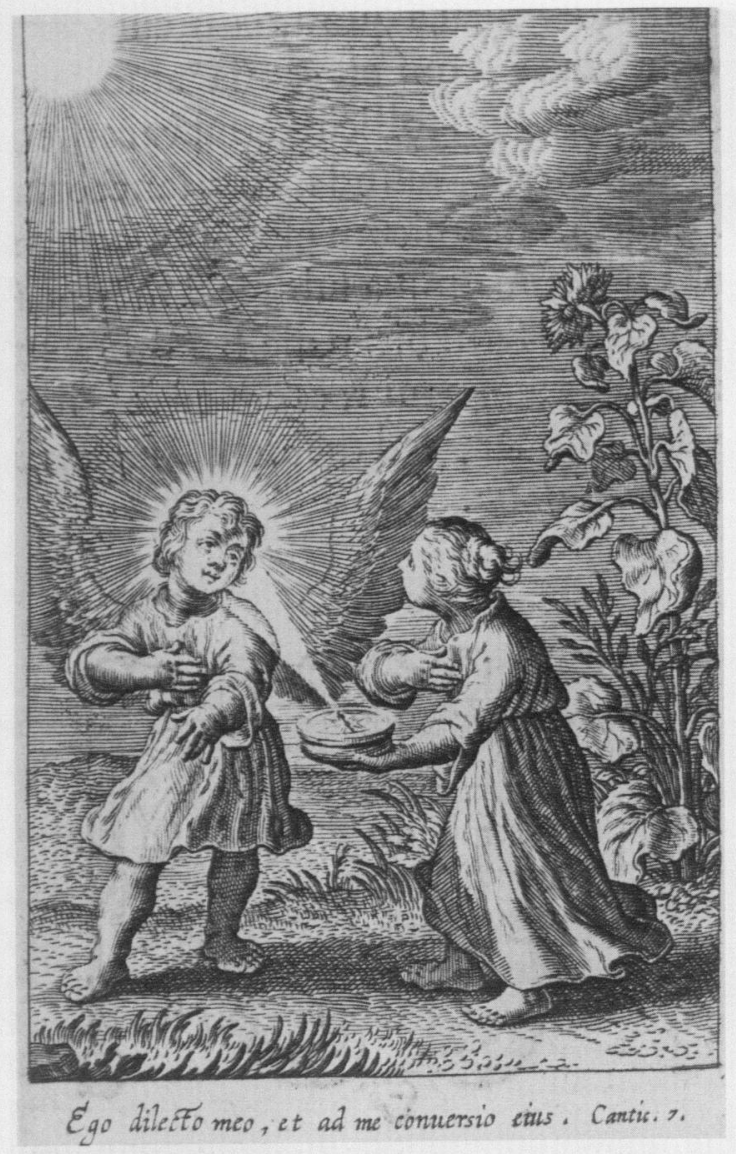

2. Herman Hugo, Pia desideria emblematis illustrata, Kupferstich, I628. Antwerpen, vor S. 297
Königs versehen war, wurde dem Künstler am 20. April des Jahres 1633 überreicht. ${ }^{8}$ Diese Tatsache mag zu der traditionellen Datierung des Gemäldes in die Jahre $1632 / 33$ beigetragen haben, die sich - nach allgemeiner Einschätzung mit dem stilistischen Befund deckt.

In ikonographischer Hinsicht gibt das außergewöhnliche Bild, das sich heute in der Sammlung des Herzogs von Westminster befindet, der Forschung Rätsel auf. Schon im Jahr I900 betonte Lionel Cust die Ungewöhnlichkeit dieses enigmatischen Gemäldes und noch 1999 schrieb Judy Egerton im Katalog der Antwerpener Van Dyck-Ausstellung, daß seine Bedeutung unklar sei: »De zonnebloem heeft hier ontegenzeglijk een symbolische functie, maar wat ze precies betekent blijft een raadsel. $« 9$

Die Sonnenblume, als deren hervorragendste Eigenschaft es galt, ihre Blüte stets der Sonne zuzuwenden, stand in der Emblematik als Symbol für die Liebe zu Gott. ${ }^{10}$ Exemplarisch sei an dieser Stelle auf das verbreitetste geistliche Emblembuch des I7. Jahrhunderts verwiesen, die I628 erschienenen "Pia desideria « des Jesuiten Herman

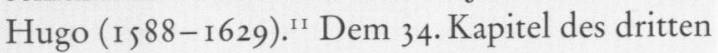
Buches ist ein von Boëtius à Bolswert (um I $580-$ 1633) gestochenes Bild vorangestellt, das die suchende Seele mit einem Kompaß zeigt, dessen Nadel auf den geflügelten »Amor divinus « weist (Abb. 2). ${ }^{12}$ Hinter den beiden Figuren steht eine Sonnenblume, die ihre Blüte dem himmlischen

Zeitschrift für Kunstgeschichte, XXXI, 1968, 27-58, bes. $36 f$. Vgl. auch Josua Bruyn u. Jan A. Emmens, De zonnebloem als embleem in een schilderijlijst, in: Bulletin van het Rijksmuseum, IV, 1956, 3-9. - Josua Bruyn u. Jan A. Emmens, The Sunflower again, in: Burlington Magazine, XCIX, 1957, $96 \mathrm{f}$.

II Herman Hugo, Pia desideria emblematis illustrata, Antwerpen 1628. »Bis 1770 sind mindestens 55 lateinische und 63 volkssprachliche Ausgaben nachzuweisen, darunter auch viele protestantische Bearbeitungen." Vgl. Wolfgang Harms, Gilbert Heß u. Dietmar Peil (Hrg.), SinnBilder-Welten, Ausst. Bayerische Staatsbibliothek, München 1999, 24f., mit weiterer Literatur.

I 2 Hugo (wie Anm. I I), vor 297.

I3 Cant. 7, I I [10].

I4 Arthur Henkel u. Albrecht Schöne (Hrg.), Emble- 
Licht zuwendet. Dem emblematischen Bild ist als Motto ein Vers aus dem Hohenlied beigegeben: "Ego dilecto meo, $\&$ ad me conuersio eius $\ll .{ }^{13}$ Die der pictura folgende Elegie erläutert, $\mathrm{da} ß$ die suchende Seele sich Gott zuwenden möge, dessen Liebe sie spüre, wie der Kompaß den Magneten und die Sonnenblume das Licht. In ähnlicher Bedeutung begegnet die Sonnenblume auch in anderen christlich moralisierenden Emblembüchern: "Das Heliotrop mit seiner goldgelben Blüte folgt wunderbarerweise stets dem Weg des wandernden Phoebus, mag er sich zum Untergang anschicken oder sich vom Aufgang erheben oder in der Mitte zwischen beiden stehen. Christus ist die Sonne des Lebens, Licht vom liebsten Licht, dem immer in Liebe zu folgen unsere heilige Pflicht ist. Glücklich, wen dieser Führer auf dem Weg zum Himmel begleitet.«14 Das Heliotrop bot sich als Gleichnis für die ewige Liebe an, da es auch als Anspielung auf die "Metamorphosen" Ovids verstanden wurde. Im vierten Buch wird dort nämlich von der in Apoll verliebten Clytia berichtet, die, in eine Blume verwandelt, Phoebus noch immer mit ihren Blicken verfolgt: "vertitur ad Solem, mutaque servat amorem. ${ }^{15}$ Das Phänomen der Hinwendung zur Sonne stand aber nicht nur als Symbol für die irdische Liebe und die Liebe zu Gott, sondern konnte auch modifiziert als Ergebenheit gegenüber einem Gönner oder als Ausdruck einer guten Regentschaft verstanden werden. ${ }^{16}$ Van Dycks Bild wurde deshalb im Sinne einer Allegorie auf das Verhältnis des Künstlers zu seinem königlichen Mäzen gedeutet: Der Künstler sonnt sich in der Gunst des

mata. Handbuch zur Sinnbildkunst des XVI. und $X V I I$. Jabrhunderts, Stuttgart 1967, Sp. $311-313$, hier bes. Sp. 3 I If.

Is Ov. met. IV, 206-270.

16 Henkel/Schöne (wie Anm. I4), Sp. 3 I 2. - Christopher Brown, Van Dyck, Oxford 1982, 147. Es trifft dabei keineswegs zu, daß diese Deutung - wie Judy Egerton, in: Ausst.-kat. Antwerpen/London (wie Ánm. 2), 244 schreibt - "vor allem die Treue eines Untertanen gegenüber seinem König oder Fürsten« bedeutet. Weit häufiger wird das Bild in theologischer Auslegung als die Hinwendung zu Gott verstanden.
Monarchen, dem er sich zuwendet wie die Sonnenblume dem Licht. Mit Blick auf die emblematische Tradition zog Robert Wark 1956 den Schluß, daß Van Dyck sein Selbstbildnis mit der Sonnenblume als Geschenk für Karl I. intendiert habe und mit diesem Gemälde, nicht zuletzt durch das Präsentieren der ihm dedizierten Kette, seine Verehrung für den Monarchen zum Ausdruck bringen wollte. ${ }^{17}$ Dieser Deutung schloß sich auch Eric Larsen an, der 1988 schrieb, daß hier der Künstler gezeigt sei, der im Lichte königlicher Gnade bade: $\ldots<. . .>$ the sun of Charles I shining upon his painter. $\alpha^{18}$

Diese royalistische Deutung vermag, wie zu Recht angemerkt wurde, letztlich nicht wirklich $\mathrm{zu}$ überzeugen. So ließ sich bislang in der ansonsten gut dokumentierten königlichen Sammlung kein Hinweis auf das Bild finden. Zudem habe Van Dyck zwar möglicherweise die vom König geschenkte Ehrenkette ins Bild gesetzt, nicht aber das daran angebrachte, von Diamanten gerahmte Bildnis Karls I. Dieses Medaillon fortzulassen, das den besonderen Wert der Kette ausmachte, wäre dem königlichen Mäzen vermutlich als Affront erschienen. ${ }^{19}$ Außerdem hatte Van Dyck die erste derartige Kette schon 1622 durch Herzog Vincenzo I. in Mantua (1594-1627) verliehen bekommen und eine zweite 1628 durch Erzherzogin Isabella (1566-1633), so daß es abgesehen von der stilistischen Datierung in die Zeit von Van Dycks englischem Aufenthalt keinen evidenten Hinweis auf einen Zusammenhang des Bildes mit der Verleihung der Ehrenkette durch Karl I. gibt. ${ }^{20}$ Auf der Suche nach einer schlüssigeren Deutung ist verschiedentlich

I7 Robert R. Wark, A Note on Van Dyck's Self-Portrait with a Sunflower, in: Burlington Magazine, XCVIII, $1956,53 \mathrm{f}$.

18 Larsen (wie Anm. 3), Bd. I, 372. - Brown (wie Anm. I6), 149.

I9 J. Douglas Stewart, in: Kat. Washington (wie Anm. 7),

${ }_{20} \mathrm{Zu}$ den an Van Dyck verliehenen Ketten vgl. Zirka Zaremba Filipczak, Picturing Art in Antwerp 15501700, Princeton (NJ) 1987,104 - - Cust (wie Anm. 9), 88. 


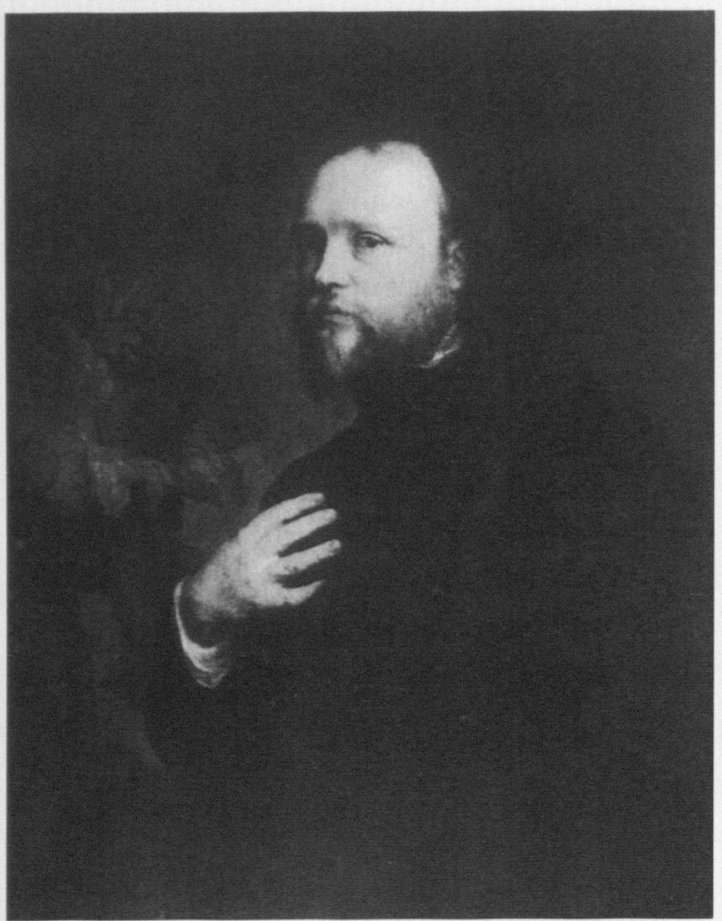

3. Anthonis Van Dyck, Sir Kenelm Digby, $\mathrm{O}$ l auf Leinwand, $100 \times 78,8 \mathrm{~cm}$. By Permission of Sir William Gladstone, Hawarden Castle

auf ein anderes Gemälde Van Dycks hingewiesen worden: Neben seinem Selbstbildnis zeigt auch das einige Jahre später geschaffene Porträt Sir

2I Sir Kenelm Digby, Öl auf Leinwand, $100 \times 78,8 \mathrm{~cm}$. By Permission of Sir William Gladstone, Hawarden Castle. Vgl. Larsen (wie Anm. 3), Bd. II, 330, Nr. 84I. - Philipp. Fehl, Access to the Ancients: Junius, Rubens and Van Dyck, in: Rolf H. Bremmer Jr. (Hrg.), Franciscus Junius F. F. and His Circle, Amsterdam 1998 (= DQR Studies in Literature, Bd. 21 ), 35-70.

22 George Vertue, Notebooks, in: Walpole Society, XXIV, 1936,38 .

23 Wark (wie Anm. 17), 53 f.

24 G. P. Bellori bezeichnet die in einem ähnlichen Bild an gleicher Stelle angebrachte Armilliarsphäre als "Impresa*. Giovanni Pietro Bellori, Le vite de pittori, scultori, ed architetti moderni, Rom 1728, i 56.

25 John Steegman, A Survey of Paintings in Welsh Houses, Bd. I, Cardiff 1957, I80.

26 Hor. epist. I, I, I I.

27 Zitiert nach: Wolfgang Schlüter (Übers.), $M r$. John Aubrey's, Esq. Lebensentwürfe, Frankfurt a.M. 1994,
Kenelm Digbys (I603-I665) den Dargestellten mit einer Sonnenblume (Abb. 3 ). ${ }^{21}$ Der englische Schriftsteller und Antiquar George Vertue (I684-1754) sah das Bild um das Jahr I730 bei Lord Sunderland auf Althorpe: "Sr Kenelm Digby. _ lenght with a sunflower at his side. at top OMNIS. IN HOC SUM «. ${ }^{22}$ Auch dieses, heute auf Harwarden Castle befindliche Gemälde ist als Anspielung auf die Beziehung des Dargestellten $\mathrm{zu}$ seinem Monarchen verstanden worden. ${ }^{23}$ Das Porträt Digbys ist, im Unterschied zu Van Dycks Selbstbildnis, hochformatig. Die links im Hintergrund gezeigte Sonnenblume erscheint dadurch nicht als optisch gleichrangiger Bildgegenstand, sondern als Attribut. ${ }^{24}$ Diese Funktion wird noch dadurch unterstrichen, daß über der Blume eine Inschrift angebracht ist. ${ }^{25}$ "[Quid verum atque decens, curo et rogo et] omnis in hoc sum «, heißt es in den Briefen des Horaz. ${ }^{26}$ In der Übersetzung von Johann Heinrich Voss (175I-1826): »Wahres und Ziemendes forsch' ich, und frag', und leb darin ganz." Horaz beschreibt in diesem Brief an seinen Gönner Maecenas, daß er Rom verlassen habe, um auf dem Land zu sich selbst zu finden. Es liegt nahe, in diesem Zitat eine Anspielung auf die Biographie des Dargestellten zu sehen: Sir Kenelm hatte sich I633, nach dem so plötzlichen wie frühen Tod seiner Frau, an das Grasham College in London zurückgezogen, um, wie sein Zeitgenosse John

126. Direkt nach deren Tod - »the second day after she was dead " - hatte Sir Kenelm Van Dyck beauftragt, ein Porträt seiner Frau auf dem Totenbett anzufertigen. Vgl. Vittorio Gabrieli, Sir Kenelm Digby, Rom I957, 246, 248. - Robert T. Peterson, Sir Kenelm Digby: The ornament of England $1603-1665$, Cambridge 1956 , 105.

28 Gabrieli (wie Anm. 27), Iorf. - Peterson (wie Anm. 27), 95, 106f., 337.

$29 \mathrm{Zu}$ Digbys theologischen Schriften vgl. zusammenfassend S. L. Lee, in: Leslie Stephen u. a. (Hrg.), Dictionary of National Biography, Bd. XV, London I 888, 62.

30 Henry Morley (Hrg.), Sir Kenelm Digby, Observations upon , Religio Medici by Sir Thomas Brown [1642], London I886, I68. Philipp Fehl (wie Anm. 2 I, s6f.) hat zu Recht darauf hingewiesen, daß die als Liebesemblem zu verstehende Sonnenblume auch als Allusion auf den Tod Venetia Digbys gelesen werden 
Aubrey (1625-1695) berichtet, »übler Nachrede \& Scheelsucht aus dem Weg zu gehen. (...) Dort trug er einen langen Trauermantel, einen hohen Hut, den Bart ungeschoren: sah aus wie ein Einsiedler. ${ }^{27}$ Digby verbrachte ganze zwei Jahre mit naturwissenschaftlichen, philosophischen und religiösen Studien. Ein Resultat dieses Aufenthaltes war, daß er 1635 zum katholischen Glauben zurückkehrte, nachdem er fünf Jahre zuvor zum Protestantismus konvertiert war. ${ }^{28}$ Seine verschiedenen religiösen Bekenntnisschriften legen den Schluß nahe, daß es Digby weniger darum ging, mit der als Attribut gewählten Blume seine royalistische Gesinnung zu dokumentieren, als vielmehr seine gewandelte religiöse Auffassung zum Ausdruck zu bringen. ${ }^{29}{ }_{1} 642$ zum Beispiel verglich Digby in einem Kommentar zur »Religio Medici« des Arztes und Philosophen Thomas Brown (I605-1682) das Wirken der göttlichen Gnade mit den Strahlen der Sonne: "But since the nature of superior and excellent things is to shower down their propitious influences, wheresoever there is a capacity of receiving them, and no obstacle to keep them out, like the sun that illuminateth the whole air, if no cloud, or solid opacous body intervene, it followeth clearly, that this infinite sun of justice, this immense ocean of goodness, cannot choose but environ with this beams, and replenish even beyond satiety with his delightsome waters,

kann, die »like Dante's Beatrice or Petrarch's Laura, is also his link to God «.

3I Bellori (wie Anm. 24), i 56.

32 Sir Kenelm Digby, Öl auf Leinwand, $106,5 \times 8 \mathrm{I} \mathrm{cm}$. Sir Felix Cassel, Putteridge Bury, Luton. Vgl. Larsen (wie Anm. 3), Bd. II, 330, Nr.840. Weitere Versionen ebd. 484 , Nr. A $218 / 1-3$. - J. Douglas Stewart, in: Ausst.-kat. Washington (wie Anm. 7), 7of. - Arthur K. Wheelock, ebd., 253 f., Nr. 64 .

33 Hor. carm. III, 3, 7. - Die Übersetzung wiederum nach J. H. Voss. - Eine bildliche Umsetzung des Verses bei Otto Van Veen, Q. Horatii Flacci Emblemata Imaginibus incisis, Notisque illustrata, Antwerpen I607, 70 f.

34 Vgl. zur Deutung des Horaz-Verses: Dorothea Gall, Die Bilder der borazischen Lyrik, Königstein/Ts. I981, I I s.

35 Vgl. zu den neostoischen Konzepten göttlicher providentia zusammenfassend: Mark Morford, Stoics and Neostoics: Rubens and the Circle of Lipsius, Princeton a soul so prepared and tempered to receive them. $\ll^{3 \circ}$

Vor diesem Hintergrund erklärt sich die Sonnenblume auf seinem Porträt sicherlich als Symbol für die Hinwendung zu Gott. Diesen Schluß legt auch ein weiteres Porträt Digbys von der Hand Van Dycks nahe, das schon von Giovanni Pietro Bellori $(1613-1696)$ erwähnt wird: $" \mathrm{Di}$ pinselo in più modi, armato, ed in abito di Filosofo con l'impresa di una sfera rotta\&. ${ }^{11}$ Dieses Gemälde, das den Dargestellten wim Gewand eines Philosophen mit einer Armilliarsphäre als Symbol« zeigt, ist ebenfalls mit einem Motto versehen, das Horaz entnommen ist: ${ }^{32}$ "[Si fractus illabatur orbis] impavidum ferient [ruinae].* - "Zerschellte hoch des Aethers Wölbung, Schrecklos steht er, umkracht von Trümmern. «33 Auch hier zielt die Aussage des Mottos wieder auf die selbstgewählte Isolation des Weisen, die von Horaz in der Rezeption stoischer Philosopheme zum Vorbild erhoben wird. ${ }^{34}$ Zugleich bringt das Motto treffend die in der stoischen und neostoischen Philosophie vertretene Überzeugung von der unausweichlichen Auslieferung der irdischen Existenz an das in der göttlichen providentia vorgegebene Schicksal zum Ausdruck. ${ }^{35}$ Dazu paßt das Motiv der Sphäre, die in der emblematischen Literatur der Zeit als mit der Vanitas verbundenes Zeichen für die Suche nach überzeitlichem Wissen stand. ${ }^{36}$ In das Deutungs-

(NJ) 1991, I64-171. - Die Verknüpfung der Werke des heute allgemein als mepikuräisch « verstandenen Horaz, mit den Idealen der stoischen Philosophie, war im 17 . Jahrhundert gängige Praxis. Justus Lipsius zum Beispiel verglich sich selbst mit dem römischen Dichter (Physiologiae stoicorum libri tres, Antwerpen 1604,143 f.). Auch Otto Van Veens Emblemata Horatiana (wie Anm. 33) waren ein durch und durch neostoisches Buch. In deren Einleitung wird dabei ausdrücklich auf Lipsius *nostri saeculi (...) phoenix", als Autorität auf dem Gebiet stoischer Philosophie, verwiesen. Lipsius selbst hatte in seinem 1584 erstmals veröffentlichten philosophischen Hauptwerk $D e$ constantia die Sonnenblume als Gleichnis für die Hinwendung zu Gott verwand: „Atque vt heliotropium, \& flores quidam, ingenio suo semper ad solem: sic Ratio ad deum obuersa est, \& origine sui.* Vgl. Florian Neumann (Hrg.), Justus Lipsius, De Constantia, Mainz 1998, 34 . 


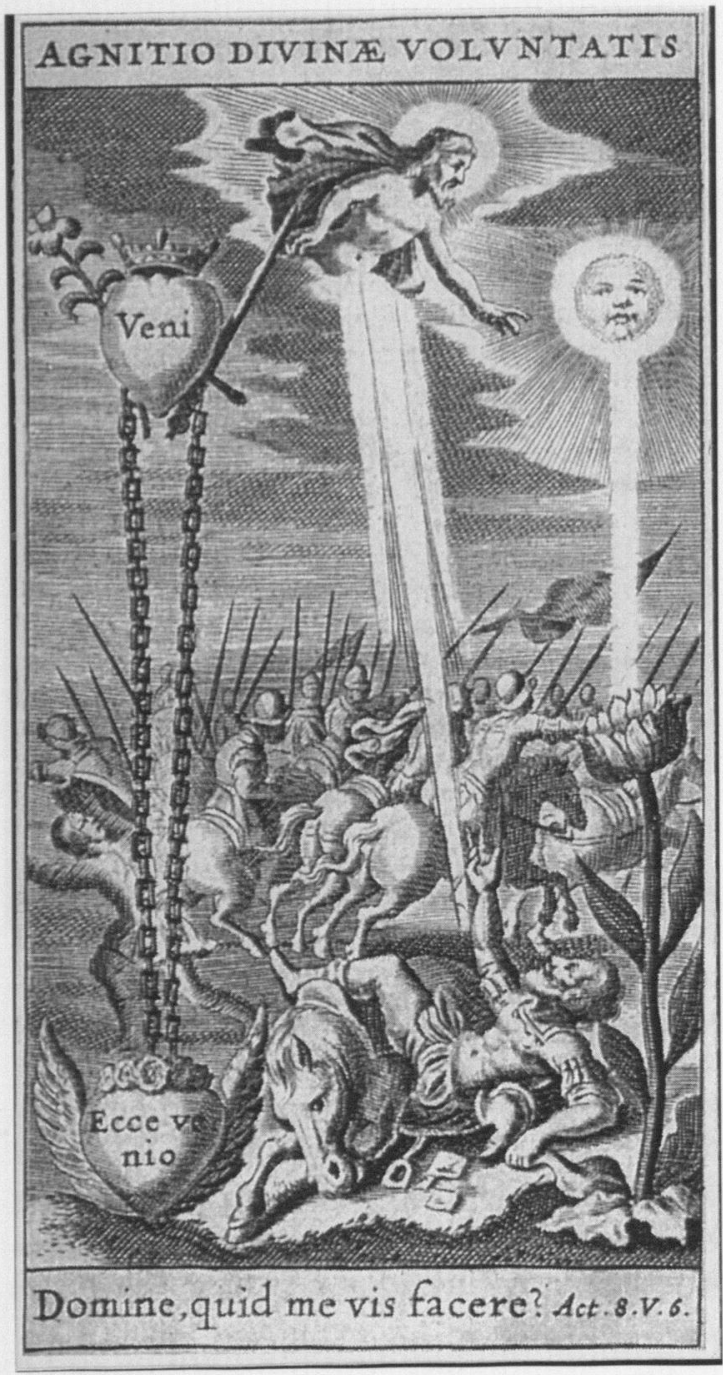

4. Jeremias Drexel, Heliotropium - sen conformatio bumanae voluntatis cum divina, Kupferstich, 1627. München, Frontispiz
36 Im ersten Emblem von Gabriel Rollenhagens Nucleus emblematum begegnet ein Gelehrter, der eine Sphäre hochhält. Ihm gegenüber sitzt an einem Tisch der Tod. Das umlaufend gestochene Motto erläutert die leicht begreifbare Lehre: "Disce bonas artes, et opes contemne caducas | Vivitur ingenio, caetera mortis erunt.« Vgl. Carsten-Peter Warncke (Hrg.), Gabriel Rollenhagen, Sinn-Bilder: Ein Tugendspiegel, Dortmund I983, 12. - Henkel/Schöne (wie Anm. 14), Sp. I05sf. - Zur Vanitas-Deutung auch Fehl (wie Anm. 21), $55 \mathrm{ff}$.

37 Von der Bedeutung der Gebärdensprache handelt schema des um Erkenntnis ringenden, weltfernen Philosophen, der sich Gott zuwendet, fügt sich auch der in beiden Bildern begegnende Gestus der Beteuerung. Die rechte Hand ist jeweils über der Brust in den Saum des Gewandes gegraben, ein Motiv, das schon von der antiken Rhetorik als Beteuerungsgeste empfohlen wird.37 Im Zusammenspiel der Einzelmotive erscheinen die Bildnisse Digbys als Ausdruck seines Glaubens und seiner philosophischen Grundhaltung.

Diese Deutung läßt sich wohl kaum ungebrochen auf Van Dycks Selbstbildnis übertragen. Auch hier mag die Sonnenblume als religiöse Anspielung auf die Hinwendung zu Gott verstanden werden, doch würde diese Interpretation wohl kaum das ostentative Vorzeigen der goldenen Kette erklären oder den so fordernd über die Schulter aus dem Bild gewandten Blick. Im Rahmen einer Untersuchung zu Rembrandts »Aristoteles « ist Julius Held der Bedeutung und Konnotation des Motivs der goldenen Kette nachgegangen. ${ }^{38}$ Neben dem Verweis auf die bei Homer erwähnte Kette, die Zeus vor den anderen Göttern auszeichnete, verwies er auf den bereits für die Antike bezeugten Brauch, besondere Verdienste durch Ehrenketten zu belohnen und Helden mit solchen Ketten auszuzeichnen. ${ }^{39}$ Konrad Hoffmann hatte schon 1968 darauf hingewiesen, daß die Sonnenblume und die Kette in der Titelillustration zu Jeremias Drexels (I 8 I-I638) Erbaungsbuch »Heliotropium - seu conformatio humanae voluntatis cum divina aus dem Jahr I627 zusammen erscheinen (Abb.4): Während die Sonnenblume auch dort wieder für die Hinwendung zu Gott steht, bedeutet die Kette die

Franciscus Junius, De pictura veterum, Amsterdam 1637, I80, in Anlehnung an Quintilian mit einer bemerkenswerten Akzentverlagerung: »decor quoque a gestu atque motu venit « (Quint. inst. XI, 3, 68), hingegegen »omnis certe decor a gestu atque motu venit bei Junius, a.a.O., 178. - Allgemein zur Gebärdensprache auch: Ursula Maier-Eichhorn, Die Gestikulation in Quintilians Rhetorik, (Phil. Diss. München 1986), Frankfurt a.M. u.a. I989 (= Europäische Hochschulschriften, Reihe is, Bd. XLI).

38 Julius S. Held, Rembrandt Studies, Princeton 1969, $32-4 \mathrm{I}$. 
symbolische Verbindung der Erlösungsgewißheit - »ecce venio - mit der heilsgeschichtlichen Vergangenheit - »veni ${ }^{\circ}$. Da die Kette jedoch bei Van Dyck nicht im Kontext der christlichen Herz-Emblematik gezeigt ist, sah Hoffmann die allgemeine Übereinstimmung beider Bilder allein in der "Zuwendung des Menschen zum Höheren, bei Van Dyck in spezifischer Anwendung des Gedankens auf die Malerei, die der in der Natur offenbarten Schönheit folgt «.40 Schon George Vertue, der Van Dycks Gemälde 1725 neben anderen Selbstbildnissen verzeichnete, deutete es als Allegorie der Kunst und schrieb von dem Bild: »<...> having a Sun Flower, alluding to his imitation of the beautys of nature and flower, is said to follow the light of the Sun. « $^{41}$ Dieser Beschreibung Vertues folgend wurde das ungewöhnliche Thema auch von der neueren Forschung als Huldigung an die Malerei verstanden. ${ }^{42}$ Den Anfang machten hier Josua Bruyn und Jan Emmens, die 1956, ausgehend von einem in Amsterdam bewahrten Bilderrahmen aus dem 17. Jahrhundert, der mit einer Sonnenblume dekoriert ist, dem Motiv eine umfassende ikonographische Studie widmeten. Sie wurde zum Ausgangspunkt aller weiteren Bemühungen um die Interpretation von Van Dycks Selbstbildnis. Der reich dekorierte Rahmen mit der Sonnenblume gehört zu einem Selbstbildnis des Malers Ferdinand Bol (1616-1680), der sich stehend, frontal dem Betrachter zugewandt, zeigt (Abb. 5).43 Den linken Arm stützt er lässig auf eine Skulptur, einen kauernden, schlafenden Amor. Nach einem umfassenden Exkurs zur Ikonographie der Sonnenblume kamen Bruyn

39 Vgl. auch Filipczak (wie Anm. 20), 104- 108.

40 Hoffmann (wie Anm. I0), 37.

41 George Vertue, Notebooks, in: Walpole Society, XX, 1932, 107.

42 Zuletzt: Ursula Härting, Gartenglück auf flämischen Gemälden des 16. und 17 . Jahrhunderts, in: Weltkunst, LXIX, I 999, $306 \mathrm{f}$.

43 Ferdinand Bol, Selbstbildnis. Öl auf Leinwand, $128 \times$ $104 \mathrm{~cm}$. Amsterdam, Rijksmuseum, Inv.-Nr. $\mathrm{A}_{42}$. Vgl. Pieter J. J. van Thiel u.a. (Hrg.), All the paintings of the Rijksmuseum in Amsterdam: A completely illustrated catalogue, Amsterdam u. Maarsen 1976, i 23. und Emmens zu dem Schluß, daß mde zonnebloem als verliefde en getrouwe volgeling ook te zijn gebruikt om de navolging van de natuur door de schilderkunst te symboliseren $\alpha_{4}{ }^{44} \mathrm{Als}$ Beleg für diese These führten sie ein Gedicht Joost van den Vondels (1587-1679) aus dem Jahre 1654 an. In dessen Inwyjinge der Schilderkunste op Sint Lukas Feest « heißt es, daß die Malkunst intuitiv und emphatisch den Schönheiten der Natur folge, so wie die Sonnenblume sich nach dem Licht der Sonne richte, die ihr auch die sonnengelbe Farbe verleihe.45 Als weiteren, frühen Beweis dafür, daß die Sonnenblume ein Symbol der Kunst sei, führten Bruyn und Emmens dann das Selbstbildnis Van Dycks an. Wie das Selbstporträt Bols zeige es die Blume und den Künstler und so stehe außer Frage, „dat Van Dijck's zelfportret met de zonnebloem wel zeker een toespeling op de schilderkunst bevat ${ }^{.}{ }^{46}$ Van Dyck war bereits dreizehn Jahre tot, als Vondels "Inwyjinge entstand, er kann diesen Text also nicht gekannt haben. Und ob die Blume über Ferdinand Bols Selbstbildnis als "Lob der Malkunst « intendiert war, ist wohl eher fraglich. Eddy de Jongh hat den berühmten Rahmen mit der Sonnenblume überzeugend mit der zweiten Heirat Bols im Jahre 1669 in Verbindung gebracht und zu Recht darauf hingewiesen, daß Bol sich auf dem Gemälde nicht als Maler zeigt und daß er diesen Beruf nach seiner Heirat sogar aufgegeben habe. ${ }^{77}$ De Jongh brachte dafür den schlafenden Putto mit der Sonnenblume in Verbindung; beide werden im Kontext der Eheschließung zum Symbol der Liebe und der ehelichen Treue..$^{8}$ Dieser Beitrag wurde von der Van

44 Bruyn/Emmens 1956 (wie Anm. ro), 6.

45 Bruyn/Emmens I956 (wie Anm. 10), 7 .

46 Bruyn/Emmens 1956 (wie Anm. 10), 8.

47 Eddy de Jongh, Bol vincit amorem, in: Simiolus, XII, $198 \mathrm{I} / 82$, I $47-16 \mathrm{I}$.

${ }_{4}^{8}$ Vgl. auch P. J. J. van Thiel, in: ders. u. C. J. de Bruyn Kops (Hrg.), Prijst de Lijst: De hollandse schilderijlijst in de zeventiende eeuw, Ausst.-kat. Rijksmuseum, Amsterdam 1984, 234, Nr.6r. 
Dyck-Forschung nicht zur Kenntnis genommen. Die Sonnenblume in Van Dycks Gemälde wurde allgemein als Symbol der Kunst verstanden, wobei die Deutung von Bruyn und Emmens meist - mehr oder weniger direkt - mit der royalistischen Interpretation verbunden wurde. So schrieb Hans-Joachim Raupp 1984: "Van Dyck präsentiert sich hier als Personifikation seiner Kunst, die im Fürstendienst ihre besondere Würde erhält. « 49

Es dürfte außer Frage stehen, daß Van Dycks Gemälde - unabhängig von der Konnotation ikonographischer Details wie der Kette oder der Sonnenblume - als Zeugnis seiner Kunst und Probe seiner Kunstfertigkeit zu lesen ist. Van Dyck war noch nicht lange in England, als er sein Selbstbildnis malte. Er war auf der Suche nach fürstlichen Auftraggebern und zugleich darauf aus, seinen Ruhm zu mehren. Dazu gehörte nach Überzeugung jener, die sich theoretisch mit Fragen des künstlerischen Ruhms beschäftigten, vor allem Glück. Dieser Meinung war auch der am Hofe Arundels als Bibliothekar tätige niederländische Kunsttheoretiker Franciscus Junius ( $1589-1677$ ), ${ }^{\circ}$ der jedoch in seiner Schrift »De pictura veterum « zugleich feststellte, »daß [nicht] der ganze Ruhm des Künstlers vom Glück abhange. Denn zuerst muß er nothwendig mit einem vorzüglichen Probestück der vollendeten Kunst sich die Thüre des Rums eröffnen. , Niemand überläßt einem sein Bildnis zu mahlen, bis verschiedene Beispiele dessen Geschicklichkeit bewährt haben (Cornel. Celsus in Epist. ad C. Iulium Callistum), Und Socrates sagt (apud Xenophontem Libr. III. Apomn.): ,Wir stellen die Bildhauer vorher auf die Probe und trauen

49 Hans-Joachim Raupp, Untersuchungen zu Künstlerbildnis und Künstlerdarstellung in den Niederlanden im 17 . Jabrhundert, Hildesheim u.a. 1984 (= Studien zur Kunstgeschichte, Bd.XXV), 212. Für die Verknüpfung der Deutungen vgl. auch Judy Egerton, in: Ausst.-kat. Antwerpen/London (wie Anm. 2), 244, Nr. 66.

so $\mathrm{Zu}$ Junius am Hofe Arundels vgl. Howarth (wie Anm. 2), 75-96, 149-170. - Raupp (wie Anm.49), $97 \mathrm{f}$.

5 I Franciscus Junius, Von der Mablerey der Alten, Bres- nicht ihren Worten: erst, wenn wir sehen, daß einer die vorigen Statuen schön gebildet, glauben wir, er werde die anderen nicht schlechter verfertigen.«'I Als ein solches »Probestück« bot sich ein Selbstbildnis in besonderem Maße an, da es dem Künstler erlaubte, den direkten Vergleich des Porträts mit dem Modell zu gewährleisten, um auf diese Weise seine Fertigkeiten unter Beweis zu stellen. Zugleich waren Selbstbildnisse bei Kunstfreunden und Sammlern beliebt, denn mit dem Abbild des Künstlers dokumentierten sie zugleich seine »Handschrift", so daß sie als Zeugnisse künstlerischen Stils besonders geeignet waren.52 Es bleibt jedoch die Frage offen, warum diese Probe der Kunstfertigkeit Van Dyck ausgerechnet im gleichberechtigten Gegenüber zu einer Sonnenblume zeigt, die sich, wie zuletzt Ursula Härting richtig anmerkte, nicht der Sonne, dem Himmel oder einem Symbol fürstlicher Macht zuwendet, sondern dem Künstler selbst. ${ }^{53}$

Vor dem naheliegenden Schluß, daß Van Dyck selbst die Sonne sein könnte, der die Blume sich zuneigt, schreckten die Interpreten bislang zurück. ${ }^{54}$ Dabei wurde von der Van Dyck-Forschung übersehen, daß die panegyrische Kunstliteratur immer wieder berühmte Künstler mit der Sonne verglich." Im Jahre I 557 sah zum Beispiel Lodovico Dolce ( $1508-1568$ ) in Michelangelo (1475-I 564) eine Sonne unter den Künstlern und er stand mit dieser Einschätzung nicht allein. ${ }^{6}$ Schon I $54^{8}$ hatte der Verleger Michele Tramezino in der Widmung der italienischen Übersetzung der »Roma Trionfante « des Biondo da Forli den "göttlichen « Michelangelo mit der Sonne verglichen. 57 Im 17. Jahrhundert pries man beispielsweise Albrecht Dürer (147I-I 528) als

lau 1770, 343. - Junius (wie Anm. 37), 127: »Non statuimus tamen totam artificium famam ex fortunâ pendere. necesse est enim, ut primùm insigni aliquo exactissim $x$ artis specimine januam famæ sibi aperiant. nemo imaginem suam pingendam committit, nisi probato prius artifici per quedam experimenta. Corn. Celsus in epist. ad C. Iulium Callistum."

52 Belege dafür, daß es sich dabei nicht allein um ein theoretisches Konzept, sondern um eine tatsächlich geübte künstlerische Praxis handelt, bei Stefanie Marschke, Künstlerbildnisse und Selbstporträts: Stu- 


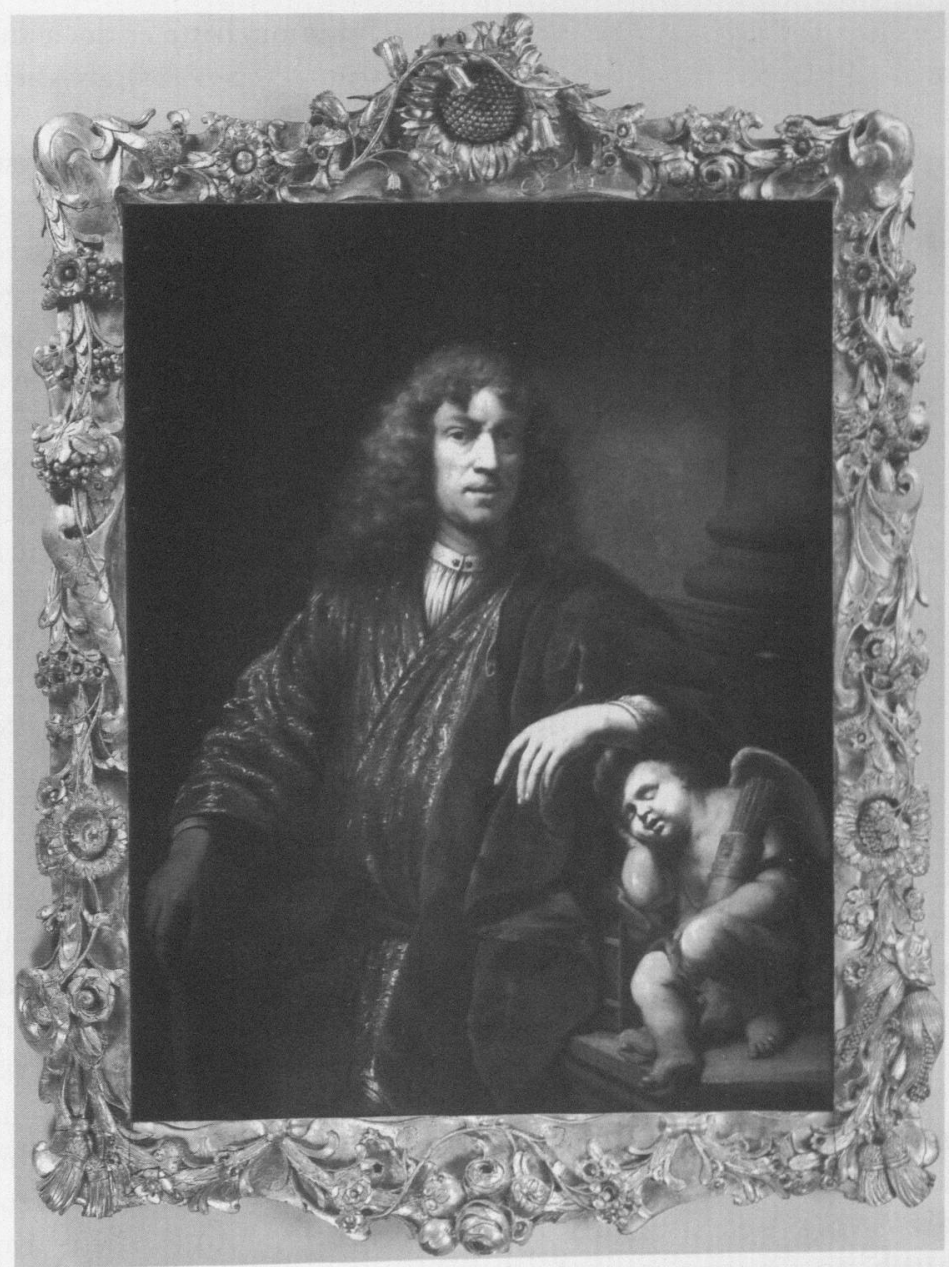

5. Ferdinand Bol, Selbstbildnis,

Öl auf Leinwand, ${ }_{2} 8 \times 104 \mathrm{~cm}$. Amsterdam, Rijksmuseum

Sonne. So bezeichnete Joachim von Sandrart (I606-I688) den großen Nürnberger in einer von ihm verfaßten Grabinschrift als "Artium

dien zu ibren Funktionen von der Antike bis zur Renaissance, Weimar 1998, 239-244. - Joanna WoodsMarsden, Renaissance Self-Portraiture: The Visual Construction of Identity and the Social Status of the Artist, New Haven/London 1998, 133-137.

53 Härting (wie Anm. 42), 306.

54 Michael Levey, Painting at Court, New York 1971, I26, hat in der Van Dyck-Forschung als einziger gemutmaßt, daß Van Dyck die Sonne sein könnte, ohne diese Vermutung jedoch zu begründen.

ss Donath de Chapeaurouge, Einführung in die Ge-
Lumen und "Sol Artificium $« .5^{8}$ Auch Sandrart selbst wurde 1675 »von desselben dienstbaren Vettern und Discipeln« die Ehre zuteil, eine

schichte der christlichen Symbole, Darmstadt 1987 , I4 If., kommt das Verdienst zu, erstmals auf diese Tatsache hingewiesen zu haben.

56 Lodovico Dolce, Dialogo della Pittura [1557], in: Paola Barocchi (Hrg.), Trattati d'arte del Cinquecento, Bd. I, Bari 1960, 147.

57 Ernst Steinmann u. Heinrich Pogatscher, Dokumente und Forschungen zu Michelangelo, in: Repertorium für Kunstwissenschaft, XXIX, 1906, $42 \mathrm{I}$.

58 Heinz Lüdecke u. Susanne Heiland, Dürer und die Nachwelt, Berlin 1955, $108 \mathrm{f}$. 


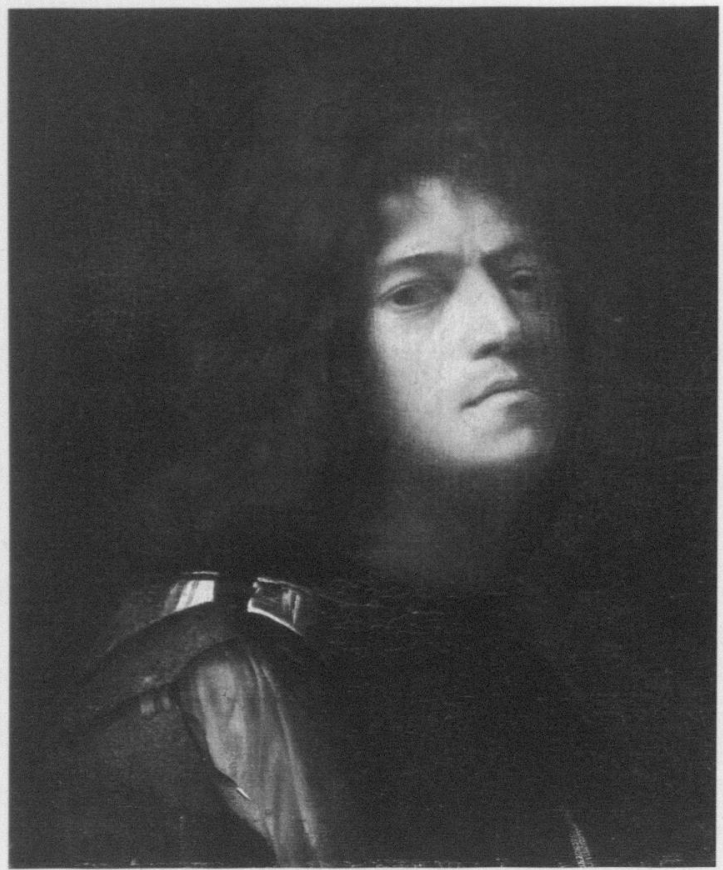

6. Giorgione, Selbstbildnis,

Öl auf Leinwand, $52 \times 43 \mathrm{~cm}$.

Braunschweig, Herzog Anton Ulrich-Museum

"Sonne « genannt zu werden. Vermutlich verfaßte Sandrart selbst jenen Text, in dem es heißt, daß »dieser erleuchtete Geist nahme wol recht an sich die Eigenschaft der Sonne, welche nicht allein leuchtet, sondern auch mit unverdrossenem Lauf die Häuser des Himmels durchkutschet und dieselben erleuchtet ${ }^{59} \mathrm{Er}$ stellte sich damit in eine

59 A. R. Peltzer (Hrg.), Joachim von Sandrarts Academie der Bau-, Bild- und Mahlerey-Künste von 1675 . Leben der berühmten Maler, Bildhauer und Baumeister, München $1925,20$.

60 Peltzer (wie Anm. 59), 51.

6I Arnold Houbraken, Groote Schouburg der Nederlantsche Konstschilders en Schilderessen, Bd. I, Amsterdam 1718,183 .

62 Raupp (wie Anm.49), I8I-219. - Ders., in: Selbstbildnisse und Künstlerporträts von Lucas van Leyden bis Anton Raphael Mengs, Ausst.-kat. Herzog Anton Ulrich-Museum, Braunschweig 1980, I8-21.

63 Giorgione, Selbstbildnis, Öl auf Leinwand, $52 \times$ $43 \mathrm{~cm}$. Braunschweig, Herzog Anton Ulrich-Museum, Inv.-Nr. 454. Vgl. Ausst.-kat. Braunschweig (wie Anm. 62), 38-42, Nr. I. gute Tradition, hatte er doch auch schon Jan van Eyck (um I390-I44I) als »helleuchtende Mahlersonne bezeichnet. $^{60}$ Auch auf Van Dyck wurde dieser Vergleich angewandt: In seiner "Groote Schouburg « schreibt Arnold Houbraken (I660-I719), daß Rubens den jungen Van Dyck nur deshalb nach Italien gesandt habe, »damit die Strahlen seiner aufgehenden Sonne sein eigenes Licht nicht verdunkeln möchten ${ }^{\text {61 }}{ }^{\text {I }} \mathrm{Daß}$ Van Dyck sich selbst mit der Sonne verglich, indem er sich mit der Sonnenblume malte, mag man mit Blick auf diese literarischen Zeugnisse kaum mehr bezweifeln. Auch die auffällige Kopfwendung mag im Kontext des Bildes als Hinweis darauf verstanden werden, daß Van Dyck sich als "Maler-Sonne" verstand, da dem Blick über die Schulter als Kennzeichen von Genialität symbolische Funktion zukam. HansJoachim Raupp ist diesem Motiv nachgegangen, das sich längst als Zeichen für die künstlerische Inventio etabliert hatte, als Van Dycks Bild entstand. ${ }^{62}$ Sicher ist es in diesem Zusammenhang kein Zufall, daß der Künstler sich selbst auf die linke Seite gestellt hat, nähert er sich damit doch zugleich Giorgiones (um I478-I510) 》Selbstbildnis als David« an, dem Bild, das am Anfang der langen Reihe von Künstlerbildnissen steht, in denen uns die »genialische « Wendung des Kopfes begegnet (Abb.6). ${ }^{6}$ Diese Kopfwendung hat einerseits eine rhetorische Funktion, indem sie dem Bildnis eine unmittelbare, »sprechende « Wirkung gibt. Auf der anderen Seite kann die

64 Raupp (wie Anm. 49), I9of. - Zum Gegensatz von Kopf und Leib vgl. Cicero, der sich in den Tusculinischen Gesprächen (Cic. Tusc. I, I0, 20) über Platon äußert (Plat. Tim. 69 E). - In diesem Sinne fordert Karel van Mander die Maler auf, Kopf und Leib ihrer Figuren stets in unterschiedliche Richtungen weisen zu lassen. Vgl. Hessel Miedema (Hrg.), Karel van Mander, Den grondt der edel vrij schilder-const, Utrecht 1973, Bd. I, II 4 ; Bd. II, 45.

6s Giovanni Paolo Lomazzo, Idea dell Tempio della Pittura, Mailand ${ }^{2}$ I 590,44 .

66 Tizian, Mann in Blau, Öl auf Leinwand, 8I,2 $\times$ $66,3 \mathrm{~cm}$. London, National Gallery. Vgl. Harold E. Wethey, The Paintings of Titian: II. The Portraits, London I971, 103 f., Nr. 40. - Das Bild erscheint I644 in einem Inventar von Van Dycks Besitz. Vgl. Jenny 
starke Akzentuierung der unterschiedlichen Ausrichtung von Kopf und Körper auch als Ausdruck des Gegensatzes von Geist und Fleisch gedeutet werden. Das ostentative Abwenden des Kopfes, wie der in die Ferne schweifende Blick versinnbildlichen so ein Schauen auf eine höhere, allem Irdischen ferne, vollkommen geistige Existenz. ${ }^{64}$ Zugleich mag man die Haltung, die Van Dyck sich in seinem Selbstbildnis gab, auch als aemulatio mit Tizian (1477-1576) verstehen, einem Künstler, den Giovanni Paolo Lomazzo (I538-1600) als Sonne unter den Malern gerühmt hatte. ${ }^{65}$ Tizian hatte seinen sogenannten "Ariost " in dieser Pose gezeigt, ein Bild das Van Dyck nicht nur kannte und bewunderte, sondern in späteren Jahren sogar besaß (Abb. 7). ${ }^{66}$ In seinem Bestreben, eine dem Gemälde Tizians vergleichbare kompositorische Lösung zu finden, nähert Van Dyck seine Haltung der des Dichters an und zeigt sich dadurch als zu dichterischer Inspiration befähigter Maler-Poet. Der Rückgriff auf traditionelle Bildnisschemata und -motive bleibt dabei nicht auf die Pose beschränkt. Auch die hinter dem Künstler gezeigte Wand ist als Allusion eines traditionellen Motivs zu lesen. Sie erscheint als Abbreviatur jener Säule, die sich in der Porträtikonographie als Tugendsymbol und Zeichen der »Constantia « etabliert hatte. ${ }^{67}$

Ein auffälliges Detail des Bildes ist das im Rücken geschlitzte purpurrote Gewand, in dem der Künstler sich zeigt. Augenscheinlich handelt es sich nicht um ein allägliches Kleidungsstück.

Müller-Rostock, Ein Verzeichnis von Bildern aus dem Besitze des van Dyck, in: Zeitschrift für bildende Kunst, N.F. XXXIII, 1922, 22-24.

67 Henkel/Schöne (wie Anm. I 4), Sp. I 227 f. - Justus C. Müller Hofstede, Peter Paul Rubens I $577^{-1640 .}$ Selbstbildnis und Selbstverständnis, in: Ekkehard Mai u. Hans Vlieghe (Hrg.), Von Bruegel bis Rubens: Das goldene Jabrhundert der flämischen Malerei, Ausst.kat. Wallraf-Richartz-Museum, Köln 1992, I03-I20. - Justus Müller Hofstede, Rubens und das Constantia-Ideal: Das Selbstbildnis von 1623 , in: Matthias Winner (Hrg.), Der Künstler über sich in seinem Werk. Internationales Symposium der Bibliotheca Hertziana, Rom 1989. Weinheim 1992 (= Acta Humaniora, Bd. VI), $365-405$.

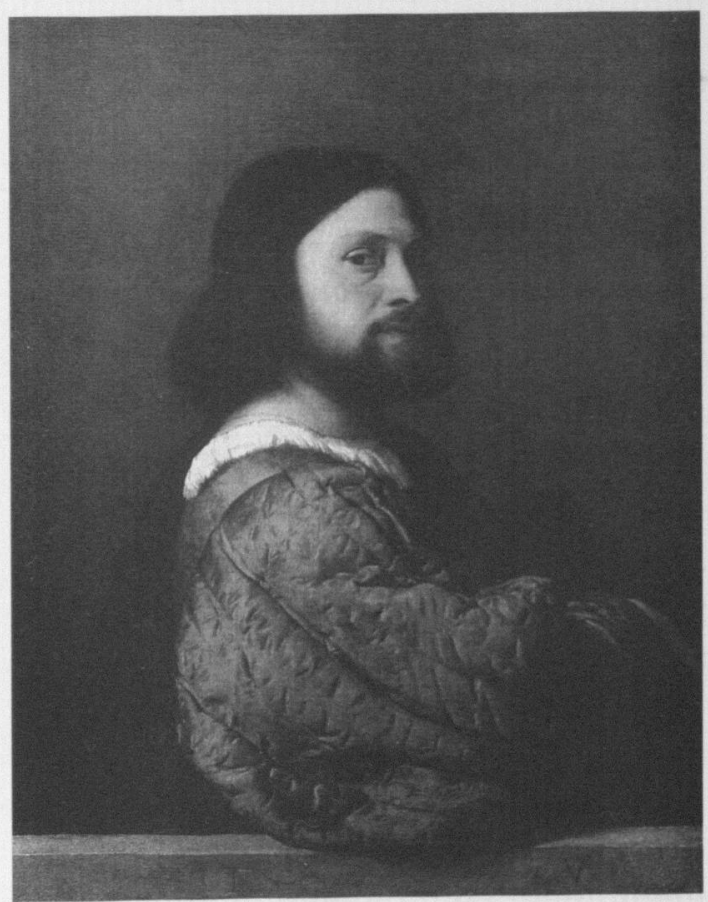

7. Tizian, Mann in Blau, Öl auf Leinwand, $8 \mathrm{r}, 2 \times 66,3 \mathrm{~cm}$. London, National Gallery

$\mathrm{Zu}$ leuchtend rot ist seine Farbe, deren Intensität durch die grellweißen Lichtreflexe und die tiefdunklen Schatten noch gesteigert wird. ${ }^{68}$ In der Kunsttheorie der frühen Neuzeit wird die intensive rote Farbe als wirksames Mittel angesprochen, die Aufmerksamkeit des Betrachters zu

68 Auf Van Dycks um 1640 entstandenem Doppelporträt von Thomas Wentworth, I $I^{\text {st }}$ Earl of Stafford (1593-1641), und Sir Philip Mainwaring (1589I66I) ist letzterer in einem ähnlichen roten Gewand gezeigt. Vgl. Larsen (wie Anm. 3), Bd. II, 394, Nr. 1005. - Millar (wie Anm. 3), 97, Nr. 57. Allgemein zu geschlitzten Gewändern in der Mode des 17. Jahrhunderts: Frithjof van Thienen, Das Kostüm in der Blütezeit Hollands 1600-1660, Berlin 1930, 63. Max von Boehn, Menschen und Moden im 17. Jahrbundert, München '1964, 122. - James Laver, Die Mode, Wien, München u. Zürich 1970, I 14. 
wecken und seinen Blick zu lenken. So schreibt etwa Paolo Lomazzo in seinem "Trattato dell' arte de la pittura a aus dem Jahre I 584 , daß die Farbe Rot im Bild eine gewisse "Schärfe der Beobachtung " hervornufe. ${ }^{69} \mathrm{Daß}$ sich die farbige Wirkung im Kontrast verstärkt, wußte man schon in der Antike, worauf Franciscus Junius 1637 hinwies: „Deshalb schreibt man schwarz auf weiß; weiß aber und mit golden Buchstaben auf schwarz; denn entgegengesetzte Dinge neben einander fallen mehr in die Augen. ${ }^{70}$ So mag eine Begründung für die starke rote Farbigkeit darin liegen, daß Van Dycks Bildnis zusammen mit anderen in einer Gemälde- oder Porträtgalerie hing. In diesem Kontext kam der ausgeprägten Farbigkeit die Aufgabe zu, den Blick der Betrachter auf dieses besondere Bildnis zu lenken. ${ }^{71}$

Es entsprach dem Geschmack der Zeit, komplizierte Sinnzusammenhänge, die jenseits der sichtbaren Realität lagen, in Bildern auszudrükken, und die starke Farbigkeit war sicher mehr als ein Mittel zur Blicklenkung. Vielmehr konnte die Farbe auch direkt mit einer Bedeutung verbunden sein. So schrieb der Kunsttheoretiker Karel van Mander (I 548-1606) in seinem "Lehrgedicht« für junge Maler, daß die Farben zahlreiche Inhalte transportieren könnten. Das Rot zum Beispiel stehe für "Hoheit, Mut und Kühnheit«. Zugleich versinnbildliche die rote Farbe

69 Giovanni Paolo Lomazzo, Trattato dell'arte de la pittura. Diviso in sette libri. Ne' quali si contiene tutta la Theorica, $\mathcal{E}$ la prattica d'essa pittura, Mailand i 584 , 205: $\gg I 1$ rosso che denota vendetta, si adoperaua ancora appresso gl'antichi da ricoprire i cataletti ne gli quali erano riposti quelli che valorosamente haueuano combattuto, come si legge in Homero, \& in Virgilio." Allgemein zur roten Farbe und ihrer Bedeutung auch Ulrich Heinen, Rubens zwischen Predigt und Kunst: Der Hochaltar der Walburgenkirche in Antwerpen (Diss. Köln 1994), Weimar 1996, I 8 I f., der auch auf Junius hinweist.

70 Junius (wie Anm. 51), 441. - Junius (wie Anm. 37), 167: *Quapropter \& nigra scriptura in albis id recipientibus fit; Alba vero scriptura $\&$ aurea è contrario in nigro: contrarium enim contrario appositum magis elucet. "

7 I Vgl. dazu auch: Nils Büttner, in: Der Krieg als Person: Herzog Christian im Bildnis von Paulus Moreelse, Ausst.-kat. Herzog Anton Ulrich-Museum, Braunschweig 2000, 102. den Planeten Mars und die Tugend der Liebe. Auch könne man die Farben zu den menschlichen Lebensaltern in Beziehung setzen, wobei dann das Rot für den Mann zwischen dreißig und fünfzig stehe. Darüber hinaus setzt van Mander, einer älteren Konvention folgend, die Farben auch zu den vier Temperamenten und den vier Jahreszeiten in Beziehung: Das Rot konnte dabei für den Sanguiniker genauso stehen wie für den Sommer. ${ }^{72}$

Um mit Blick auf ein derart komplexes Deutungsangebot eine gewisse Verständlichkeit zu gewährleisten, bedienten sich die Maler der auch beim Publikum verbreiteten Handbücher, die das Wissen um den emblematischen Gehalt und die allegorischen Inhalte von Bildern in übersichtlicher Form verfügbar machten und dadurch konventionalisierten. Eine Schlüsselstellung nahm dabei die »Iconologia" des Cesare Ripa (ca. I $560-1622$ ) ein. Diese erstmals I 593 publizierte Sammlung von Sinnbildern war weniger als Vorlagensammlung für die gestalterische Praxis intendiert, denn als methodische Unterweisung für alle Gebildeten. ${ }^{33}$ Ripas Sammlung fand reißenden Absatz. Sie erlebte etliche Auflagen und wurde in beinahe alle europäischen Sprachen übersetzt. ${ }^{74}$ Auch Van Dyck kannte dieses Buch und wird gewußt haben, welche allegorische Deutung in der »Iconologia« dem roten Gewand

72 Vgl. Miedema (wie Anm. 64), Bd. II, 622-644: »Ghelijck in den Schilden t'Gout schoon en gloedick | Geldom en hoocheyt can te kennen gheven/ | t' silver puerheyt en gherechticheyt goedick/ | Beteyckent t'Root hoocheyt/ en coenheyt moedich/ (...) Het Blaeuw trouwheyt/ en wetenschap bedreven: (...) Onder de Planeten is by der Sonnen | t' Goudt gheleken/ en by de Mane connen / Wy t'Silver verstaen/ en Mars by het roode/ (...) Met dees Verwen/ al de daghen der weken/ | Oock de seven Deuchden/ sonder ontweken/ | t' Gheloove by t' Goudt/ Hope goedertierich | By t'Silver/ by t' Roode de Liefde vierich. (...) Ghelijckt Ghetempertheyt in ' $t$ wesen matich: | Oack by dees Verwen ghelijcktmen de seven | Ouderdommen van dit menschlijke leven. | Een kind tot seven Jaer oudt naer het baren/ | Is 't Silver oft wot onnoosel en pertich/ | t' Blaeuw tot vijftien Jaer de Jeucht onervaren/ | $t$ 'Goudt-gheel den Jonghelingh tot twintich Jaren/ | En t'Groen den Jonghman tot den Jaren dertich/ | t'Roodt tot vijftich Jaer/ noch een 
zugeschrieben wurde. ${ }^{75}$ Es war ausgerechnet "honore« - die Ehre -, die Ripa als einen schönen, in Purpur gewandeten Jüngling beschreibt »Een schoon Iongelingh in purper gekleet «: "Hy wordt jongh en schoon gemaeckt, overmidts hy sonder eenige woorden of fluytreedenen, sich aengenaem maeckt. En het Purpre kleed, beeld de alderhooghste Eere af, wesende een Koninklijck cieraet $\ll^{76}$ Als Ergänzung dieser Attribute konnten eine goldene Halskette oder ein goldenes Armband dienen: "De gulde keetens aen hals en armen, waeren oude Eertyckens, en wierden van de Romeynen gegeven tot belooninge, van die sich dapper, in den Krïgh, hadden gedragen, gelijck Plinius verhaeld. «77 Zugleich war in Ripas "Iconologia « die Goldkette auch mit der Malerei verbunden, indem die Personifikation der "Pictura « als eine Frauengestalt »met een goude Keeten aen den hals $«$ beschrieben wird. $7^{8}$ So mag die auf dem Gemälde von Van Dyck so stolz vorgezeigte Kette einerseits auf seine Kunst und seinen künstlerischen Anspruch anspielen. Darüber hinaus bezeugt sie auch die Wertschätzung durch seine weltlichen Gönner und vielleicht sogar seinen Anspruch auf Divinität, war die goldene Kette doch schon in der Antike als Insigne der Götter verstanden worden.

In merkwürdigem Widerspruch zur emphatischen Gesamtaussage des Bildes scheinen die

Man cloeckhertich/ | (...)|Vier aerden oft Mensch complerien blijcken | Oock vier verwen ghelijck/ eerst den Sanguijnen | Vol bloedts by t'Roodt/ by t'Blaeuw den Colerijcken $|(\ldots)|$ Oock is/ soo men d'Elementen begheerde (...) (ssr) (...) t'Roodt t'vyer/ $t^{\prime}$ Blaeuw lockt/ $t$ 'Wit water/ en $t$ 'Swart d'eerde. T'Groen bediedt den Lenten in s'Jaers vier tijden/ | t'Roodt den Somer/ midts 't Sonnesschijns heet bran$\operatorname{den} /|(\ldots)|$ Dus wijsen de Verwen aen veel verstan-

73 Carsten-Peter Warncke, Sprechende Bilder - sichtbare Worte: Das Bildverständnis in der früben Neuzeit, Wiesbaden 1987 (= Wolfenbütteler Forschungen, Bd. XXXIII), i 95 .

74 Zur Editionsgeschichte vgl. Jochen Becker, in: Cesare Ripa, Iconologia of uytbeeldingen des Verstands, Amsterdam 1644 (= Reprint: Soest 197 I), I-XXXIII.

$75 \mathrm{Zu}$ Van Dycks Verwendung der Iconologia vgl. Ausst.-kat. Washington (wie Anm. 7), 253.

76 Ripa (wie Anm. 74), 116 f. dunklen Wolken zu stehen, die hinter der Sonnenblume den blauen Himmel verdüstern. Diese Wolkenwand ist in der Literatur als negativ konnotiert gedeutet worden. So fühlte sich Zirka Zaremba Filipczak an einen Brief erinnert, den Peter Paul Rubens (1577-I640) am 18. Februar des Jahres 1627 an Pierre Dupuy sandte: "La calumnia del viaggio mio in Inghilterra si dissipò finalmente come la nebbia al sole, et mi trovo colla gracia divina e la mia innocenca nella solita buona gracia de' padroni, che si sono scusati meco di questo suspetto. «79 So wie Rubens die nach den Kalamitäten der England-Reise eingetretene Verbesserung mit dem Aufklaren des Himmels verglich, habe Van Dyck mit der Beschattung der Sonnenblume seine Furcht vor der Zukunft zum Ausdruck gebracht: »If Van Dyck was experiencing or fearing difficulties similar to those encountered by Rubens, he may have given symbolic expression to his anxieties by placing the sunflower in shadow. « ${ }^{80}$ Tatsächlich lassen sich die Wolken in Van Dycks Bild wohl eher als so positives wie sinnfälliges Bild künstlerischer Invenzione und Imaginationskraft deuten. So erscheinen die Wolken - nubes - in der Stichunterschrift zu dem von Rubens entworfenen Frontispiz der von Justus Lipsius (1 547-1606) besorgten Ausgabe der Werke Senecas, als Sinnbild der Imagination (Abb. 8). ${ }^{81}$ Der Stich zeigt, in einem

77 Ripa (wie Anm.74), I16. Der Hinweis darauf, daß ausländische Soldaten mit goldenen Ketten ausgezeichnet wurden bei Plin. nat. XXXIII, 10, 37.

78 Ripa (wie Anm. 74), 452. Vgl. auch Ausst.-kat. Antwerpen/London (wie Anm. 2), 244.

79 Max Rooses u. Ch. Ruelens (Hrg.), Correspondance de Rubens et documents épistolaires concernant sa vie et ses auvres, Bd. IV, Soest o.J., 36. Vgl. auch Ruth Saunders Magurn, The Letters of Peter Paul Rubens, Cambridge (Mass.) 1955, 171, die in ihrer Übersetzung aus dem Nebel - "la nebbia - Wolken werden ließ: "The calumny aboute my trip to England has finally been dissipated like clouds before the sun. «

80 Filipczak (wie Anm. 20), 104. - Es sei hier nur am Rande angemerkt, daß auch in der Emblematik die Sonne hinter den Wolken positiv konnotiert war. Vgl. Henkel/Schöne (wie Anm. 14), Sp. 23-25.

8I Cornelis Galle nach Peter Paul Rubens, Vortitel mit dem Porträt des Justus Lipsius, in: L. Annaei Senecae (...) Opera omnia. Antwerpen 1615 . Vgl. J. Richard 


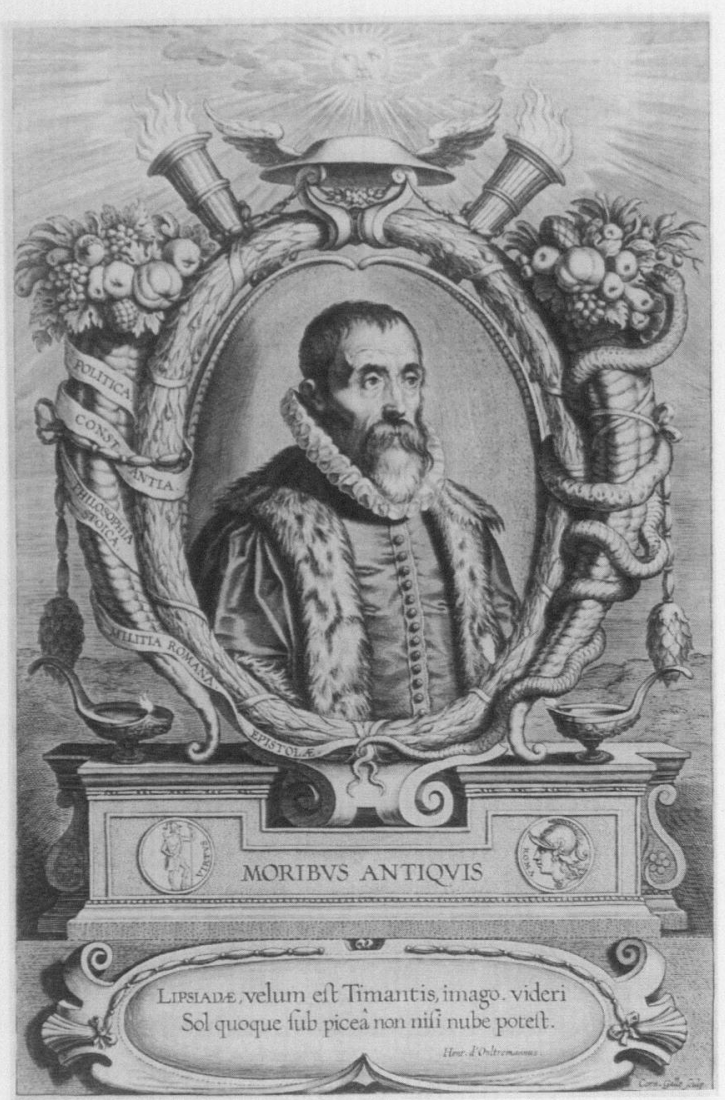

8. Cornelis Galle nach Peter Paul Rubens, L. Annaei Senecae ... Opera omnia ..., Kupferstich, I6 I , Antwerpen, Vortitel

mit Fackeln und Füllhörnern geschmückten Oval, unter dem Petasos Merkurs, das Bildnis des Philosophen Lipsius, das auf einem von Öllampen geschmückten Podest präsentiert wird. »Lipsiadae, velum est Timantis, imago. videri |

Judson u. Carl Van de Velde, Book Illustrations and Title-pages, Brüssel/London 1977 (= Corpus Rubenianum Ludwig Burchard, Bd.XXI), Bd. I, I 57 f., Nr. 30. - Morford (wie Anm. 35), I $82 \mathrm{f}$.

82 Der Kleine Pauly: Lexikon der Antike, Bd. V, München 1979, 838. - Quint. inst. II, I3, 13. - Val. Max. VIII, i I u. a. - Zur Rezeption dieses Topos vgl. auch Heinen (wie Anm. 69), 2 I, I 87, Anm. 61.

83 Vgl. dazu auch Ulrich Heinen, Rubens und die Leidenschaften, Weimar 2001 (im Druck).

84 Junius (wie Anm. 37), 147: "Quintiliano lib IV. cap. 2
Sol quoque sub piceâ non nisi nube potest « lautet die von Henri d'Outreman ( I 546-I60s) verfaßte Subscriptio der Darstellung. Die Sentenz spielt auf den antiken Topos vom Maler Timanthes an, der den unaussprechlichen Schmerz des über die Opferung seiner Tochter Iphigenie trauernden Menelaos zum Ausdruck brachte, indem er dessen Haupt durch ein Tuch verbarg, so daß der starke Affekt nur in der Phantasie des Betrachters wirksam wurde. ${ }^{82} \mathrm{Da}$ Lipsius verstorben war, empfahl d'Outreman dem Anhänger seiner Philosophie (Lipsiadae), dessen gestochenes Bildnis als Tuch des Timanthes, da mit dem Tode des Philosophen dessen Weisheit nicht mehr unmittelbar sichtbar sei. Und so, wie man auch mit einer Fackel die Sonne nicht zu finden vermöge mit der d'Outreman Lipsius hier vergleicht -, so ließe sich doch im Widerschein der Wolken deren Licht erahnen. Mit den beiden Fackeln und einer die Wolken durchbrechenden Sonne wird diese Idee am oberen Rand des Stiches ins Bild gesetzt. ${ }^{{ }_{3}}$ Auf Van Dycks Selbstbildnis übertragen, das die Sonne unter den Künstlern zeigt, ließe sich die Sonne hinter den Wolken als Zeichen dafür lesen, daß dieses Gemälde nurmehr einen Reflex wiedergibt, der jedoch in der Vorstellung des Betrachters einen vitalen Eindruck zu wecken vermag. Doch so, wie der gleißend helle Rand der Wolken doch nur einen Widerschein von der Sonne Pracht bedeutet, so ist auch Van Dycks gemaltes Abbild nur ein Abglanz seiner realen Existenz. Mit dieser Anspielung auf die eigene ausdrucksmächtige Vergegenwärtigung erreicht Van Dyck jene Magnificentia, die nach Franciscus Junius das höchste künstlerische Ideal bedeutete. ${ }^{8}{ }_{4}$ Zugleich läßt sich vermuten,

dicitur magnificentia. Plinio juniori lib. VI epist. 2 I \& lib. IX ep. 26 granditas vocatur, \& maximam arti gratiam autoritatemque conciliat. debet enim Pictura plurimum gravitatis habere, et omnio omnia in se continere, quae pertinent ad amplificandam."

85 Aus den Bildern des Apelles - "pinxit et, quae pingi non possunt « (Plin. nat. XXXV, 96) - vermochte man mehr herauszulesen, als er hineingemalt hatte. Zur Interpretation dieser Stelle vgl. Walter S. Melion, Shaping the Netherlandish canon: Karel van Mander's Schilder-boeck, Chicago 1991, 174-184. - Auch der 
daß Van Dyck mit der Wolkenmetapher jenes »in omnibus eius operibus intelligitur plus semper quam pingitur« ins Bild setzen wollte, das die kunsttheoretische Literatur seit der Antike nur den Größten der Malerei zubilligte. ${ }^{85}$

Diese Deutung läßt sich noch um einen weiteren Aspekt ergänzen: Die von Van Dyck so naturalistisch wiedergegebene Sonnenblume wurde von Rembert Dodoens (I5I6/I8-i585) als »Chrysanthemum Perunianum « in die Literatur

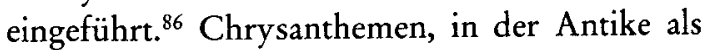
"Heliochrysum« bekannt, galten von alters her als Pflanzen mit besonderen Eigenschaften: "Sie welken niemals«, schrieb Plinius secundus (um 23-79 n. Chr.), »man bekränzt deshalb die Götter damit ${ }^{87}$ In der emblematischen Literatur wird zudem die Tatsache betont, daß diese Pflanzen »unabhängig« seien und an "steinigen und schrecklichen Orten blühen ${ }^{88}$ Der Blume wurden damit Eigenschaften zugeschrieben, die der mit den Idealen der stoischen Philosophie vertraute Van Dyck in der Gegenüberstellung als Tugenden für sich beanspruchte. So verkörpert die Blume nicht nur den Spiegel der Sonne, wodurch sie mittelbar auf die Käufer der Bilder Van Dycks anspielt, sondern auch ein Sinnbild seiner Virtus. Zugleich gilt es daran zu erinnern, $\mathrm{da} ß$ die peruanische Chrysantheme nicht nur im übertragenen Sinne ein würdiger Schmuck der Götter war: Sonnenblumen waren im 17.Jahrhundert noch rar und entsprechend teuer. Erst einige Jahre nach der Entdeckung Amerikas in Europa eingeführt, war die außergewöhnliche Pflanze zu Van Dycks Zeit nur in wenigen Gärten zu finden. Als größte unter den bekannten Blumen war die kostbare Rarität deshalb ein

Philosoph Lipsius hoffte, daß in seinen Schriften mehr zu finden sei, als er hineingelegt habe. Vgl. Aloïs Gerlo (Hrg.), Iusti Lipsi Epistolae, Bd. I, Brüssel 1978,189 .

86 Rembert Dodonaeus, Florum et coronarium odoratumque nonnullarum berbarum bistoria, Antwerpen $1568,295$.

87 Plin. nat. XXI, 168.

88 Philippo Pincinello, Mundus Symbolicus, Köln 1729, Buch 2, 630, Nr. sif. trefflicher Widerpart für einen Hofkünstler, der sich als Sonne am Firmament der Kunst sah.

Was Van Dyck mit seinem Selbstbildnis mit der Sonnenblume für sich in Anspruch nahm, findet eine Entsprechung in der lebenspraktischen Inszenierung seines künstlerischen Ruhmes. Neben vielfältigen Ehrungen und einem üppigen Einkommen hatte Van Dyck erreicht, was zuvor kaum einem Maler gelungen war: $\mathrm{Er}$ führte, im gleichberechtigten Nebeneinander mit den englischen Aristokraten, das Leben eines Adeligen. "An Pracht wetteiferte er mit Parrhasios«, schrieb sein Zeitgenosse Giovanni Pietro Bellori, »er hielt Diener, Kutschen, Pferde, Musiker, Sänger und Spaßmacher, welche all die Würdenträger, Ritter und Damen unterhielten, die jeden Tag in sein Haus kamen, um ihr Bildnis malen zu lassen. Weiterhin ließ er ihnen üppige Mahlzeiten bereiten, die ihn 30 Scudi am Tag kosteten. $\ll^{89}$ Belloris Anspielung auf Plinius mögen zumindest die gebildeten Zeitgenossen verstanden haben. Im 35. Band der "Naturalis historia « wird nämlich nicht nur berichtet, daß Parrhasios ein hervorragender Maler und Zeichner war, der sich über die Maßen gut auf das Porträtieren verstand - "argumentum quoque ingenioso", sondern auch, daß er anmaßend gewesen sei - "sed quo nemo insolentius usus sit gloria artis«: »wohl keiner nutzte anmaßender den Ruhm in seiner Kunst, denn er legte sich auch Beinamen $\mathrm{zu}$, indem er sich als verwöhnten Lebemann und in anderen Versen als Fürsten der Kunst bezeichnete, die er zur Vollendung gebracht habe; vor allem aber [sagte er], daß er von Apollon abstamme. ${ }^{\circ \circ}$ Der von Bellori aufgerufene Topos vom Maler, der sich als Sohn Apol-

89 Bellori (wie Anm. 24), 155: „Contrastava egli con la magnificenza di Parrasio, tenendo servi, carrozze, cavalli, suonatori, musici, e buffoni, e con questi trattenimenti dava luogo a tutti li maggiori personaggi, Cavalieri, e Dame, che venivano giornalmente a farsi rittrare in casa sua. Di più trattenendosi questi, apprestava loro lautissime vivando alla sua tavola con ispesa di trenta scudi il giono.« - Für die Übersetzung vgl. Ausst.-kat. Antwerpen/London (wie Anm. 2), 28 .

90 Plin. nat. XXXV, 71. 


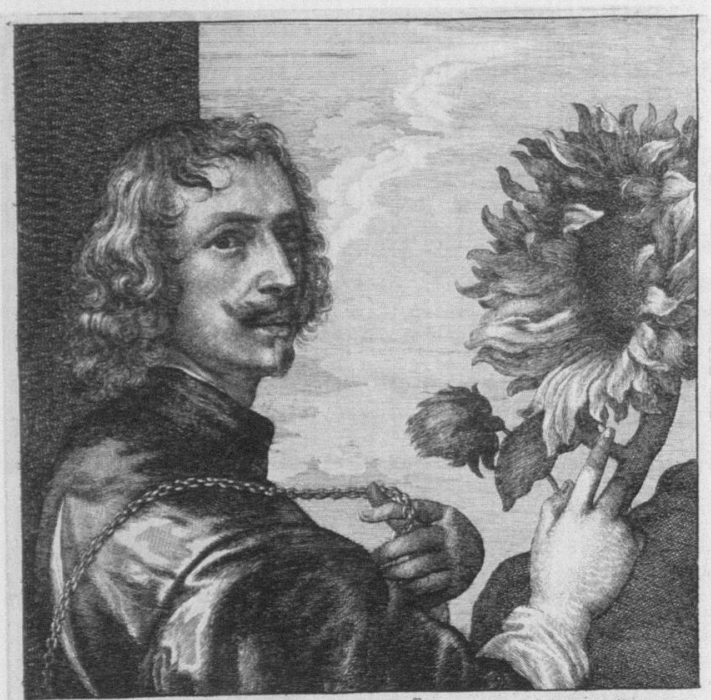

DNo: Ioha nNi Evelino Gene: Anglo, Artis PictVra Anuatori do Admiratori Karimo, Amico de Patrono furo fidelifs 1 mode be

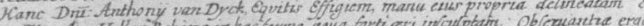

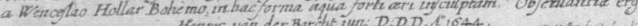
Antoverbotions

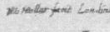

9. Wenzel Hollar, Bildnis Van Dycks mit einer Sonnenblume, Radierung, $136 \times 114 \mathrm{~mm}$

lons bezeichnete, verstärkt nur den Eindruck, daß Van Dyck in seinem Selbstbildnis sich Phoebus, der Sonne selbst, verglich, als er sich mit der Sonnenblume malte. Sein Bild bekundet damit nicht nur sein künstlerisches Selbstverständnis, sondern ist zugleich Ausdruck seines individuellen Geltungsanspruches. Es scheint offensichtlich, daß Van Dyck durch sein Selbstbildnis den ästhetischen Augenschein als Argument für die

91 Wenzel Hollar, Bildnis Van Dycks mit einer Sonnenblume. Radierung, I36 × II $4 \mathrm{~mm}$. Gustav Parthey, Wenzel Hollar: Beschreibendes Verzeichnis seiner Kupferstiche, Berlin 1853, 303, Nr. 1393. - Richard Pennington, $A$ desciptive catalogue of the etched work of Wenceslaus Hollar (1607-1677), Cambridge 1982, 239, Nr. 1393. - Nils Büttner, in: Ursula Härting (Hrg.), Gärten und Höfe der Rubenszeit, Ausst.-kat. Gustav Lübcke Museum, Hamm 2000, 323 f., Nr. 129.

92 "D[omi]no: Iohanni Evelino Gene:[ro] ${ }^{\text {so }}$ Anglo, Artis Pictvræ | Amatori \& Admìratorí Maximo, Amico \& Patrono suo fidelissimo etc | Hanc D[omi]ni: Anthonÿ van Dyck, Equitis Effigiem, manu eius propria delineata \& | a Wenceslao Hollar Bohèmo, in hac forma aqua forti æri insculptam. Observantix ergo; | Henricq van
Zubilligung gesellschaftlichen Ansehens instrumentalisierte.

Trotz der klaren ikonographischen Aussage bleibt die einstige Bestimmung des Bildes unklar. Vermutlich war auch mit diesem Porträt die Hoffnung verbunden, den in der Malerei zum Ausdruck gebrachten Anspruch im Sinne persönlicher Memoria in die Zukunft hinein zu verlängern und die einmal für sich reklamierte gesellschaftliche Position über Generationen hin dauerhaft vorzutragen. Genauso spricht sicher nichts gegen die Vermutung, daß Van Dyck sein Selbstbildnis als eine Probe seines Könnens anfertigte. Offen bleibt die Frage, für welches Publikum und welchen Rezipientenkreis er seine Darstellung bestimmt hatte. Bislang haben sich leider keine dokumentarischen Belege auffinden lassen, die etwas darüber aussagen könnten, wer das Bild im 17. Jahrhundert besaß. Den einzigen vagen Hinweis liefert eine Radierung, die der böhmische Graphiker Wenzel Hollar (16071677) geschaffen hat (Abb.9).91 Hollars Druck gibt Van Dycks berühmtes Selbstbildnis zwar seitenrichtig wieder, jedoch in seinen Proportionen verändert: Das breit gelagerte Querformat des Gemäldes ist auf einen beinahe quadratischen Ausschnitt verengt. Der Inhalt der Darstellung blieb davon augenscheinlich unberührt. Der unter der Darstellung angebrachten Inschrift zufolge widmete der Maler und Verleger Hendrick van der Borcht (1614-1654) das Blatt dem englischen Gelehrten und Schriftsteller John Evelyn (1620-1706). ${ }^{92}$ Dieser gehörte schon mit Anfang

der Borcht iun:[ior] D:[evotissime] D[ono] D.[edidcat] $\mathrm{A}[\mathrm{nn}]^{\circ} \mathrm{I} 644^{\ll .}-$ - Dem englischen Edlen, Herrn John Evelyn, dem außerordentlichen Liebhaber und Bewunderer der Malerei, seinem höchst zuverlässigen Freund und Schutzherrn usw., macht im Jahre I644 dieses Bild des Herrn Ritter Antonis Van Dyck ehrerbietigst zum Geschenk, das von dessen eigener Hand gezeichnet und von dem Böhmen Wenzel Hollar in dieser Form in Kupfer geätzt worden ist, zur Beachtung also, Hendrick van der Borcht d. J].

$93 \mathrm{Zu}$ Evelyn vgl. John Bowle, John Evelyn and His World: A Biography, London 1981. - Beatrice Saunders, John Evelyn and His Time, Oxford 1970.

$94 \mathrm{Vgl}$. Guy de la Bédoyère, The Writings of John Evelyn, Rochester 1995 . 
zwanzig zum kleinen Kreis jener englischen Virtuosi, die in der ersten Hälfte des 17.Jahrhunderts das kulturelle Leben innerhalb Europas entscheidend mitprägten. ${ }^{33}$ Evelyn war Gründungsmitglied der »Royal Society" und ein wissenschaftlicher Dilettant im besten Sinne, der sich über den Smog in London genauso Gedanken machte, wie über die Renaturierung übermäßig ausgebeuteter Wälder oder die ideale Anlage von Landschaftsgärten. Außerdem interessierte er sich für Numismatik, Architektur und die schönen Künste. ${ }^{94}$ Er sammelte auch Kunst, dilettierte als Radierer und publizierte $\mathrm{I} 662$ das erste Handbuch über druckgraphische Techniken: "Sculptura - or the history, and art of chalcography 4.95 Der Stammsitz der Familie Evelyn lag in Wotton, nur fünf Meilen von Albury entfernt, dem Landhaus der Arundels. ${ }^{66}$ Evelyn verkehrte dort regelmäßig und stand in freundschaftlichem Kontakt zu dem mehr als dreißig Jahre älteren Grafen von Arundel, Thomas Howard, dem Mäzen Van Dycks. Bei ihm wird Evelyn Wenzel Hollar und Hendrick van der Borcht kennengelernt haben, die Arundel 1636 in Dienst genommen hatte, als er in diplomatischer Mission durch Deutschland reiste und in Köln Station machte. ${ }^{97}$ Hollar, durch seine Ortskenntnis prädestiniert, begleitete Arundel auf der Weiterreise nach Prag, während van der Borcht nach Italien gesandt wurde, um dort William Petty, einen Agenten des Grafen, beim Auffinden und Ankaufen interessanter Kunstwerke zu unterstützen. Arundel war unzweifelhaft einer der passioniertesten und bedeu-

95 Eine zweite Auflage dieses Werkes, die auch eine Biographie Evelyns enthält, erschien 1775 in London.

96 Robert Harding, John Evelyn, Hendrick van der Borcht the Younger and Wenceslaus Hollar, in: Apollo, CXLIV, 1996, 39.

97 Harding (wie Anm. 96), 40. - Pennington (wie Anm. 9I), XXII.

98 Ein unvollständiges Inventar aus dem Jahre 1655 publiziert durch L. Cust u. M. Cox, Notes on Collections formed by Thomas Howard, in: The Burlington Magazine, XIX, 1911, 282-286. - Eine englische Übersetzung des Inventars, nach Künstlern sortiert bei M. F. S. Hervey, The Life Correspondende and Collections of Thomas Howard Earl of Arundel, New tendsten Sammler seiner Zeit. Seine Sammlung von Gemälden und Werken der Antike war so groß, daß eigens ein neues Galeriegebäude errichtet werden mußte, und das nur unvollständig dokumentierte Inventar seiner Gemäldegalerie zeugt von deren sagenhafter Reichhaltigkeit.98 Hollar begleitete Arundel 1637 zurück nach England, wo noch im selben Jahr auch van der Borcht eintraf. In seiner »Sculptura« pries Evelyn den Radierer Hollar über alle Maßen, "whose indefatigable works in aqua fortis do infinitely recommend themselves by the excellent choice which he hath made of the rare things of furnished out of the ARUNDelian collection, and from most of the best hands and designs; for such were those of Leonardo da Vinci, (...) Van Dyke, Rubens, Brueghel, Bassan, Elsheimer, Brouwer, ARTors, and divers other Masters of prime note, whose Drawings and paintings he faithfully copied. «99 Wenn Evelyn schreibt, daß Hollar die Werke dieser Meister "faithfully « - also: getreulich - wiedergegeben habe, so gilt es hier darauf hinzuweisen, daß die Radierungen ihre Vorlagen keinesfalls sklavisch reproduzierten. Hollar nahm sich vielmehr die Freiheit, Fehlendes zu ergänzen und in seinen Augen Fehlerhaftes zu "verbessern $«$. Auch hat er die meisten seiner Reproduktionen nach Gemälden wohl direkt auf die Radierplatte gezeichnet, wodurch es im Druck zu einer Seitenverkehrung kam. ${ }^{100}$ Arundel scheint jedoch mit der Arbeit Hollars höchst zufrieden gewesen zu sein, denn er behielt ihn auch in den folgenden Jahren in Dienst. George Vertue weiß

York 1969, App. V, 473-500. - Allgemein zur Sammlung auch Jaffé (wie Anm. 2), 3-35.

99 John Evelyn, Sculptura - or the history, and art of chalcography, London ${ }^{2}$ I 775,78 .

$100 \mathrm{Zu}$ den wenigen Ausnahmen, bei denen Hollar sich um eine seitenrichtige Wiedergabe bemüht hat, zählen seine Reproduktion des wilton Diptychons" und Van Dycks Selbstbildnis. Vgl. dazu auch: Richard Godfrey, Hollar's prints for the Earl Arundel: Copies of Lost works from the Arundel Collection, in: Apollo, CXLIV, 1996, 36-38, hier: 37 . - Ders., in: Wenceslaus Hollar. A Bobemian Artist in England, Ausst.-kat. Yale Center for British Art, New Haven 1994/95, I I - I 3 . 
darüber folgendes zu berichten: "The Earl of Arundel had several gravers constantly at work with a design to make a large volume of prints of all the pictures, drawings and other rarities which Mr Evelyn had collected. All that were done are now in the possession of his grandson, Sir John Evelyn. «101 Der geplante illustrierte Katalog der Arundel-Sammlung, von dem Vertue hier spricht, blieb unvollendet. Etliche der radierten Gemäldereproduktionen Hollars, die explizit mit dem Hinweis »ex collectione Arundeliana "versehen sind, lassen jedoch vermuten, daß tatsächlich derartige Pläne bestanden haben mögen. Der Ausbruch des englischen Bürgerkrieges und der Tod Arundels machten dem Unternehmen allerdings ein Ende. ${ }^{102}{ }_{16} 62$ floh Arundel vor den Wirren des Bürgerkrieges nach Antwerpen. Einen Teil seiner Sammlung und deren Kustos, Hendrick van der Borcht, nahm er mit. I644 kehrte auch Hollar England den Rücken und begab sich nach Antwerpen zu den Arundels. Noch im selben Jahr brach John Evelyn auf, um nach Italien zu reisen. Eine Begegnung in Antwerpen mag der äußere Anlaß für die in dasselbe Jahr datierende Widmung der Radierung nach Van Dycks Selbstbildnis gewesen sein. ${ }^{103}$

Da nicht alle Radierungen Hollars nach Werken aus dem Besitz Arundels mit einem Hinweis auf ihre Herkunft versehen sind, andererseits kein vollständiges Verzeichnis der Sammlung

IOI George Vertue, Notebooks, in: Walpole Society, XVIII, 1930, 47 existiert, wird sich wohl nicht mit letzter Sicherheit sagen lassen, ob Van Dycks Selbstbildnis dort seinen Platz hatte. Die enge Verbindung Evelyns nicht nur zu Hollar und van der Borcht, sondern auch zu Arundel und dessen Sammlung läßt es zumindest wahrscheinlich werden, daß Van Dycks Selbstbildnis mit der Sonnenblume in diesen Umkreis gehörte. Wenn sich diese These letztlich auch nicht beweisen läßt und der konkrete Bestimmungsort des Bildes vorerst unklar bleibt, ist doch mehr als deutlich, daß Van Dyck als Rezipienten seines Werkes den kleinen Kreis englischer Adeliger im Auge hatte, zu dem Thomas Howard genauso gehörte, wie John Evelyn oder Kenelm Digby: Jene so reichen wie gelehrten Aristokraten, die als gebildete Virtuosi den subtilen Anspielungsreichtum seines Selbstbildnisses nicht nur verstanden und $\mathrm{zu}$ würdigen wußten, sondern darüber hinaus als Mäzene und Auftraggeber seine Kunst förderten. Sie waren durchaus bereit, Van Dyck als Sonne am Firmament der Kunst zu sehen, galt er doch - nicht zuletzt dank seiner geschickten Inszenierung künstlerischen Ruhmes - als einer der bedeutendsten Maler seiner Zeit, und ein Werk von seiner Hand gereichte jedem Sammler zur Ehre. Van Dycks ambitioniertes Selbstbildnis war deshalb geeignet, mit seinem künstlerischen Anspruch zugleich den Ruhm seines Besitzers als Kunstkenner und Sammler zu mehren.

102 Pennington (wie Anm. 9I), XXIII-XXXI.

I03 Harding (wie Anm. 96), 40.

Abbildungsnachweis: I London, The National Trust, Foto: Photographic Survey, Courtauld Institute of Art. - 2, 8 Göttingen, Staats- und Universitätsbibliothek. - 3, 4 Göttingen, Archiv des Verfassers. - s Amsterdam, Rijksmuseum. - 6 Braunschweig, Herzog Anton Ulrich-Museum, Museumsfoto: Bernd-Peter Keiser. - 7 London, The National Gallery. - 9 Berlin, Staatliche Museen zu Berlin - Preußischer Kulturbesitz. 